\title{
Prenatal Androgen Effects as a Proximate Mechanism Underpinning Variation in Social Behavior Among Female Nonhuman Primates
}

\author{
Caroline Howlett $^{1,2} \cdot$ Brandon C. Wheeler $^{1}$
}

Received: 25 May 2020 / Accepted: 22 January 2021 / Published online: 22 March 2021

(C) The Author(s) 2021

\begin{abstract}
While the role of ecological factors in shaping primate social systems has been a central focus for decades, less attention has been given to phylogenetic relationships and the potential role of underlying proximate mechanisms. This study aimed to investigate the relationship between one such proximate mechanism, prenatal androgen effects (PAEs), and aspects of social behavior in female nonhuman primates using the 2D:4D ratio as a proxy for PAEs and phylogenetically controlled methods. In general, female 2D:4D ratios were highest in monogamous species (low inferred PAEs) and lowest in polygynandrous and polygynous species (high inferred PAEs). 2D:4D ratios also varied with the form of polygyny/polygynandry, potentially with regard to the need for competitive over cooperative behaviors and the intensity of female reproductive competition. Species characterized by female dominance had lower 2D:4D ratios than species characterized by male dominance or codominance. There were no significant relationships between 2D:4D ratio and either degree of frugivory or group size. Relationships between 2D:4D ratios and the directional consistency index and 2D:4D ratios and rates of female-female agonism were also nonsignificant although sample sizes for both of these variables were small. Female social relationships are a manifestation of complex competitive and cooperative behaviors and the results suggest that PAEs may act as a proximate mechanism underlying the expression of certain aspects of behavior in female primates in ways that are adaptive to their social system.
\end{abstract}

Keywords 2D:4D ratio - Phylogenetics · Sex hormones · Socioecology

Handling Editor: Joanna Setchell

Caroline Howlett

caroline.howlett@mail.com

1 Present address: School of Anthropology and Conservation, University of Kent, Canterbury, Kent, UK

2 Essex Pathways Department, University of Essex, Wivenhoe Park, Colchester, Essex, UK 


\section{Introduction}

A basic assumption of socioecological theory is that females compete for access to nutritional resources and males compete for access to females (Kappeler and van Schaik 2002). Predation risk and feeding competition are thought to be among the most important ecological factors that contribute to the evolution of female social relationships (van Schaik 1989; van Schaik and van Hooff 1983). Predation risk is argued to lead diurnal female primates to form groups for safety (van Schaik 1983), which in turn leads to intragroup competition for essential resources (Terborgh and Janson 1986; van Schaik 1989). Relationships among females are thought to be influenced by the type and strength of the feeding competition they face within and between their social groups, and this is affected by the distribution of resources (Chapman et al. 1995; Isbell 1991; Koenig 2002; Sterck et al. 1997).

Food intake can have important effects on a female's survival and lifetime reproductive success and so the ability to dominate and exclude competitors from food resources is advantageous under certain conditions (Sterck et al. 1997; Trivers 1972). When resources are evenly distributed or plentiful, indirect (scramble) competition is expected (Kappeler and van Schaik 2002). Display of aggressive behavior and dominance over others is not expected to be advantageous under this type of competition and so female dominance relations are expected to be ill-defined or not identifiable (Janson 1985; Janson and van Schaik 1988), and hierarchies (if detectable) are expected to be indistinct and non-linear (Sterck et al. 1997). However, when resources are clumped and monopolizable then direct (contest) competition is expected to occur (Janson and van Schaik 1988). This type of competition is likely to result in agonistic interactions between females and the formation of hierarchical social relationships (Sterck et al. 1997). Females with despotic relationships have established dominance relations with one another and linear dominance hierarchies (Sterck et al. 1997).

Egalitarian relationships are expected between females in folivorous species as the primary food resource (leaves) is thought to be evenly distributed, abundant, and therefore unmonopolizable (Isbell 1991; cf. Koenig et al. 1998). Frugivory is typically thought to favour despotic relationships because ripe fruits tend to be high-quality, monopolizable and, therefore, contestable. Some studies have shown that agonism occurs disproportionately during feeding in primates, particularly when feeding on fruits (Cords 2000; Klass and Cords 2015). Studies have purported that dietary categories (e.g., degree of frugivory) can provide information as to the contestability and distribution of food and therefore give an indication of the expected level of feeding competition within a social group (McKenna 1979; Snaith and Chapman 2007). However, in a cross-taxa analysis, the expected association between high rates of agonism and frugivory in female primates was not generally supported (Wheeler et al. 2013) and some folivorous female primates show relatively low rates of agonism but still form decided dominance relationships (Gorilla beringei: Robbins et al. 2005; Trachypithecus phayrei: Koenig et al. 2004).

In addition to the distribution and quality of food, ecology can also indirectly affect female social structure by its effect on group size (Terborgh and Janson 1986) and there is notable variation in group size across the primate Order (Campbell et al. 2011; Kappeler and van Schaik 2002). The intensity of intragroup competition levels may increase with group size (Klass and Cords 2015; Koenig and Borries 2006; Terborgh 
and Janson 1986) and studies have found that primates living in larger groups are characterized by higher rates of agonism (Cowl and Shultz 2017; Wheeler et al. 2013). Furthermore, the demographic factor, female philopatry, is thought to be involved in the formation of female relationships (Isbell 2004; Kappeler and van Schaik 2002; Sterck et al. 1997). In species in which females disperse, female relationships are predicted to be egalitarian. In species in which females remain in their natal group, relationships vary depending on the levels of intra- and intergroup contest competition (Sterck et al. 1997).

Although the broad-scale descriptive classifications of female dominance relationships used by Sterck et al. (1997) are useful, there is considerable variation in how these relationships manifest themselves between (and sometimes even within) species (Klass and Cords 2015; Wikberg et al. 2013). This observed variation is beyond the descriptive scope proposed by Sterck et al. (1997) and species often do not conform to some predictions of the socioecological models described above (Klass and Cords 2015; Robbins et al. 2005; Wheeler et al. 2013; Wikberg et al. 2013), leading researchers to position species into the categories which they most closely match. For example, in a study on a population of predominantly folivorous Colobus vellerosus (a species with facultative female dispersal: Wikberg et al. 2014), occasional foraging on temporally available, clumped foods lead females to form individualistic dominance hierarchies of intermediate strength and high directional consistency (Wikberg et al. 2013).

The shortcomings of current socioecological models highlight the importance of considering quantitative measures of female dominance behavior (e.g., hierarchical steepness and linearity, directional consistency in dominance interactions and rates of agonism), as these may better represent the variation we see across primate species (Klass and Cords 2015). Unlike hierarchical linearity and steepness (Klass and Cords 2011), the directional consistency of female dominance relationships (measured via the directional consistency index [DCI]), is not sensitive to unknown relationships and is therefore considered the most accurate measure of despotism (Koenig et al. 2013; van Hooff and Wensing 1987). Additionally, because variation in ecology alone is not able to fully explain the observed differences in agonism and dominance patterns among female primates, it is necessary to also consider the effects of phylogeny when examining the effects of ecology on behavior (Klass and Cords 2015; Thierry 2008).

Reproductive competition can be a strong selective force in females (Rosvall 2011) but most studies investigating sexual competition focus on males (Clutton-Brock 2009). Studies in primates have revealed associations between the development of female ornamentation and weaponry and the form of reproductive competition between females (Clutton-Brock and Harvey 1976; Clutton-Brock and Huchard 2013). A study in wild female chacma baboons revealed that aggression between females was associated with access to mates (Huchard and Cowlishaw 2011). Females received aggression from other female group members at higher rates when they were reproductively active (displaying a sexual swelling or being mate-guarded by a male). Where relationships between females were traditionally considered to be the result of competition for access to resources, this suggests that sexual competition also has some involvement in shaping female social relationships (Huchard and Cowlishaw 2011). When investigating aspects of intrasexual competition between females, it is thus important to consider the impacts of a species' mating system, alongside ecological factors relating to social 
structure and dominance relationships (e.g., Huchard and Cowlishaw 2011). Indeed, sexual competition, in addition to competition for access to food resources, may shape female social relationships, even in large polygynandrous primate groups in which females are the high investing sex and males are the principal competitors (Huchard and Cowlishaw 2011).

Aggression between females is typically less frequent and intense than between males (Clutton-Brock and Huchard 2013) but this general pattern is often not the case for cooperatively breeding primate species where a single dominant female is able to monopolize reproduction (Garber 1994; Saltzman et al. 2009). Among primates, cooperative breeding is largely limited to the small-bodied callitrichine monkeys characterized by monogamous or polyandrous mating systems. Variance in reproductive success may be higher among females than males in cooperative breeders and so reproductive competition is likely to be a major selective factor for monogamous and polyandrous females (Garber 1994). Indeed, in monogamous species both sexes often play a role in territory and mate defense and are therefore mostly intolerant of same-sex intruders (Garber 1994), whereas in polyandrous species, it is typically the breeding female that is intolerant of same-sex competitors and males have a more relaxed approach to each other (Garber 1994; van Hoof and van Schaik 1994). These higher stakes for females could explain why females of polyandrous and monogamous species tend to be highly territorial and intolerant of same-sex intruders (Garber 1994).

Another social factor possibly influenced by a species' ecology is the relationships between males and females. In mammalian species, male dominance over females is the norm, and this is true of most primates (Dunham 2008; Kappeler 1993; Pereira et al. 1990). In some primate species, however, the relationships between the sexes are egalitarian in nature or there is no clear dominance of one sex over the other and the sexes are described as codominant (e.g., callitrichines and gibbons; Carpenter 1940; Koba et al. 2012; Reichard and Barelli 2008; Savage et al. 1988). Such dominance appears to correlate with monogamous and polyandrous mating systems, with some exceptions (Eulemur collaris: Balestri et al. 2014; Brachyteles arachnoides: Strier 1990). Female dominance, while rare, is most prevalent among Lemuriformes (Eichmueller et al. 2013; Kappeler 1993; Pereira et al. 1990) and occurs in some haplorhines such as Pan paniscus (Parish 1994) and some species of Saimiri (Mitchell 1994), and this pattern does not appear to be associated with particular mating systems (Kappeler 1991, 1993; Petty and Drea 2015).

While the hypothesized ecological factors contributing to aspects of social relationships among females and between females and males in primates have been discussed extensively, the role that underlying proximate mechanisms may play in regulating behaviors promoting particular dominance relationships is poorly understood. In many of the hypotheses that attempt to explain the link between social variation and ecological factors, agonistic behavior plays an integral part (Klass and Cords 2015; Sterck et al. 1997). Animal studies implicate prenatal androgen effects (PAEs) as having some influence over the shaping of an individual's tendency towards future aggressive behavior (Mazur and Booth 1998), and higher PAEs have been known to increase offspring competitive abilities (Burley and Foster 2004). In species in which competition for resources is high, the ability to out-compete challengers is highly advantageous. Therefore, high PAEs may enhance competitive behaviors in female primates that live in large groups (especially those with despotic dominance relationships), and if 
degree of frugivory is indeed a good proxy for the intensity of direct competition experienced by females, then one might expect greater selection for PAEs in females of highly frugivorous species.

It is not yet known whether PAEs play a role in intersexual dominance patterns in primates. In the female dominant Hapalemur alaotrensis, females are more aggressive than males (Waeber and Hemelrijk 2003) and a study on six captive Eulemur species found that in female dominant species, females directed more dominance and aggressive behavior toward their male partner than they received whereas codominant females showed less dominance behavior than and equal rates of aggression as their male counterparts (Petty and Drea 2015). Species characterized by female dominance also had more masculine androgen profiles than females of codominant species and the authors suggest a hormonal mechanism may underlie the evolution of female dominance (Petty and Drea 2015). Therefore, in comparison to male dominated or codominant species, females belonging to species in which female dominance is the rule could be expected to be more behaviorally masculinized, as selection should favor increased expression of aggressive and competitive behavior.

The ratio between the lengths of the second and fourth digits of the hands (2D:4D ratio) is a proposed negative correlate of PAEs and positive correlate of prenatal estrogen effects (POEs) (Zheng and Cohn 2011). Artificially increasing PAEs in female Macaca mulatta resulted in masculinized (lower) right hand 2D:4D ratios, and the degree of this masculinization correlated strongly with prenatal androgen-dependent trait anogenital distance (Abbott et al. 2012; Thankamony et al. 2016), although males have been observed with higher 2D:4D ratios than females in this species (Baxter et al. 2018). In 37 species of anthropoid primate, greater sexual dimorphism in 2D:4D ratio was observed in non-pair-bonded species in comparison with pair-bonded species and all species displayed significant sex differences in 2D:4D ratio (Nelson and Shultz 2010). This pattern was not mirrored in a study investigating sexual dimorphism in the second and fourth metacarpal ratio in six species of nonhuman primate, but it is likely that the growth of the metacarpals and phalanges respond differently to PAEs (Hart 2018). Low 2D:4D ratios (inferred high PAEs) are associated with higher social rank and behaviors linked to dominance and aggression in cercopithecine female nonhuman primates (Howlett et al. 2012, 2015; Hurd et al. 2011; Nelson et al. 2010) and humans (Benderlioglu and Nelson 2004). Using classifications of female social relationships (Sterck et al. 1997), female 2D:4D ratio was found to decrease with increasing intrasexual competition levels (Nelson and Shultz 2010) and these findings are concurrent with higher PAEs being of adaptive value for female primates experiencing high levels of contest competition (Nelson and Shultz 2010).

Studies suggest there is a link between high 2D:4D ratios (low inferred PAEs) and the increased postnatal expression of behaviors linked with oestrogen and its associated neuropeptides oxytocin (OT) and vasopressin (VA) (Fink et al. 2007; Fisher et al. 2010; Williams et al. 2003). Many of the behaviors characteristic of a monogamous mating system such as pair bonding, partner preference, and parental care are all facilitated through the actions of estrogen, OT, and VA (French et al. 2018; Lee et al. 2009; Neumann 2008), potentially resulting in increased selection for reduced PAEs and/or increased POEs in monogamous and polyandrous female primates. Consistent with this, pair-bonded anthropoid primates have generally higher 2D:4D ratios (indicate lower PAEs) than non-pair-bonded species (Nelson and Shultz 2010). However, in describing 
species only in terms of pair-bonded or non-pair-bonded, much of the variation in mating systems is lost. Primates display a diverse array of mating systems and distinguishing between these (and the different forms they take) may elucidate how variation in female sexual competition levels affects the strength of selection for PAEs. Because the classifications of female social relationships used by Sterck et al. (1997) have been criticized due to inconsistencies between model predictions and observed behavior (Klass and Cords 2015; Thierry 2008; Wikberg et al. 2013) and the 2D:4D ratio measurement methods used by Nelson and Shultz (2010) could be improved upon in terms of accuracy and reliability (Allaway et al. 2009; Kemper and Schwerdtfeger 2009; Ranson et al. 2013; Voracek et al. 2007), a reexamination of the relationship between female social structure and PAEs, preferably using quantitative measures of female dominance behavior and more reliable 2D:4D ratio data, is desirable.

This study investigates variation in 2D:4D ratio in both strepsirrhine and haplorhine female primates. We investigated variation in 2D:4D ratio in female primates using improved 2D:4D measurement methods and quantitative measures of female social structure. We aimed to investigate the relationship between variation in PAEs (inferred from 2D:4D ratios) and female intrasexual competition and intersexual dominance relationships across primates. We tested five hypotheses, based on the assumption that 2D:4D ratio correlates negatively with PAEs. First, if food contestability affects female competitive relationships, females in species that depend on foods thought to elicit contest competition should face selection for higher PAEs than females in species that do not depend on such foods. Thus, we predict that highly frugivorous species have lower 2D:4D ratios than less frugivorous species. Second, if direct competition increases with group size, we predict that species that live in larger groups will display lower 2D:4D ratios than those that live in smaller groups. Third, if behavioral traits associated with higher PAEs are favored in females in species characterized by a high degree of despotism and high rates of female-female agonism, then we predict that the directional consistency in dominance interactions and rate of agonism will both be negatively related to 2D:4D ratio. Fourth, if species in which females experience higher competition for mates are likely to benefit from higher PAEs, we predict that monogamous females will have the highest 2D:4D ratios, followed by polyandrous females, with polygynous and polygynandrous females having the lowest 2D:4D ratios. Finally, PAEs play a vital role in the masculinization of behavioral tendencies (Goy et al. 1988; Pomerantz et al. 1985, 1986; Wallen 2005; Wallen and Hassett 2009), so we hypothesize that higher PAEs may be important for the maintenance of intersexual dominance relationships among primates (particularly female dominance) and predict that female 2D:4D ratios will be lowest in species in which females are the dominant sex (Table I).

\section{Methods}

\section{Study Subjects}

We collected hand images between March 2016 and November 2017 on 488 individual female primates across 71 species housed in 29 zoos, wildlife/safari parks, and primate research centres in the UK, Germany, Italy, Netherlands, Spain, and one sanctuary in South Africa. We also included published 2D:4D ratio data from 25 wild female chacma 
Table I The socioecological variables investigated and their predicted relationships with PAEs and the 2D:4D ratio in female primates

\begin{tabular}{lll}
\hline Socioecological factor & Relationship with PAEs & Relationship with 2D:4D ratio \\
\hline $\begin{array}{lll}\text { Percentage of fruit in diet } \\
\text { Group size }\end{array}$ & Positive & Negative \\
DCI & Positive & Negative \\
Rate of agonism & Positive & Negative \\
Mating system & $\begin{array}{l}\text { Positive } \\
\text { Lower in monogamy/polyandry; } \\
\text { higher in polygyny/polygynandry }\end{array}$ & $\begin{array}{c}\text { Higher in monogamy/polyandry; } \\
\text { lower in polygyny/polygynandry }\end{array}$ \\
& $\begin{array}{l}\text { Lowest in codominant species; } \\
\text { higher in male dominant species; } \\
\text { highest in female dominant species }\end{array}$ & $\begin{array}{c}\text { Highest in codominant species; } \\
\text { lower in male dominant species; } \\
\text { lowest in female dominant species }\end{array}$ \\
& \multicolumn{2}{l}{}
\end{tabular}

baboons (Papio ursinus) (Howlett et al. 2015). Animals included in the study were of juvenile (53 individuals), subadult (21 individuals), and adult (439 individuals) ages. The use of animals that are not fully mature in this study is justified as the 2D:4D ratio is fixed early in prenatal development (Galis et al. 2010) and does not change appreciably during puberty (Králik et al. 2014; Manning 2002; Manning et al. 2003, 2004).

\section{D:4D Ratio Measurements}

We used the digital photographic and computer-assisted image analysis software method as described in Howlett et al. (2015) to obtain 2D:4D ratio measurements. We collected images of primate hands using the "free photo" method as described in Howlett et al. (2015) and photographs of the ventral surface of the animals' hands were taken against a clear Perspex® sheet on occasions when animals were being handled for veterinary treatment (Fig. 1). For each individual, we identified three photographs per hand in which digits were in the optimal positions and for purposes of data reliability (Allaway et al. 2009), the first author carried out all measurements of 2D:4D ratios from these photographs using the software program ImageJ.

For each individual, we measured the second and fourth digits five times per photograph, giving a total of 15 measurements for each digit, and we used the mean of these 15 measurements as the measurement for that digit. We calculated the 2D:4D ratio of each hand by dividing the length of the second digit by the length of the fourth digit for each individual. We calculated the mean 2D:4D ratio (M2D:4D) by averaging the right 2D:4D ratio (R2D:4D) and left 2D:4D ratio (L2D:4D). We then took the mean of individual within species 2D:4D ratio measurements to obtain R2D:4D, L2D:4D, and M2D:4D data for each species. These species means are the 2D:4D ratio measures we used in analyses and the final data set comprised the R2D:4D, L2D:4D, and M2D:4D of 513 individual female primates across 71 species (Table II).

\section{Anatomical Considerations}

Variation in primate hand morphology is associated with substrate use (Jouffroy et al. 1993; Lemelin and Schmitt 1998; Richmond 2007) and so we collated substrate use 

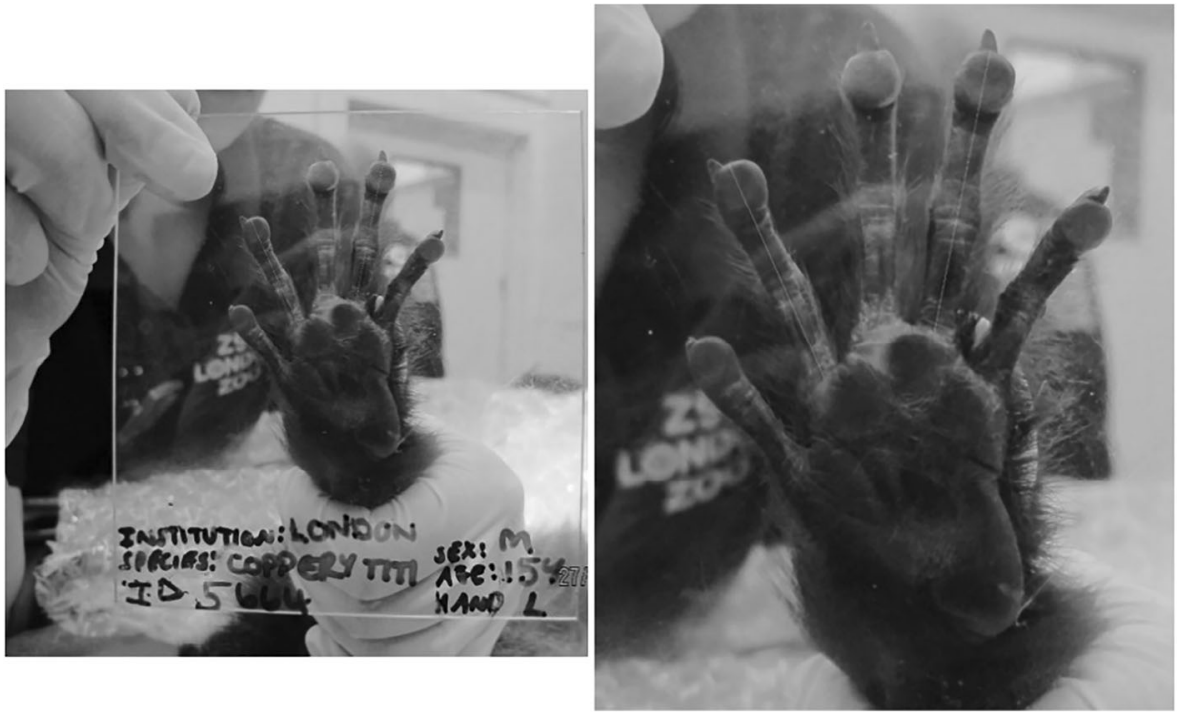

Fig. 1 Image showing an example of computer-assisted measurement of hands using ImageJ software. White lines indicate the path of measurement for each digit from the basal crease to the tip of the extended digit. The images above present a Perspex ${ }^{\circledR}$ photograph of the left hand of an anesthetized male coppery titi monkey (Callicebus cupreus).

data for each species from the literature. Primates were classified as arboreal (68-100\% arboreal), arboreal/terrestrial (34-67\% arboreal), or terrestrial (0-33\% arboreal). Where substrate use data were not available as percentages, we used categorical classifications given by the authors of the publications (Electronic Supplementary Material [ESM] Table SI).

In humans, it has been suggested that men have lower 2D:4D ratios because they have longer digits than women (Kratochvíl and Flegr 2009; Lolli et al. 2017; cf. Manning 2010), implying that a link exists between 2D:4D ratio and body size. The 2D:4D ratio is fixed early in prenatal development and is generally stable throughout postnatal growth (Galis et al. 2010; Manning and Fink 2018), making it unlikely that allometry has an extensive influence over its development. However, to account for possible effects of body size on 2D:4D ratio, we collected mean adult female body mass (in grams) data for each species and controlled for this variable in all analyses (Table II; ESM Table SII).

\section{Diet and Group Size}

To test predictions related to frugivory, we collated data from the literature on the percentage of fruit in each species' diet (Table II; ESM Table SIII). Percentage of fruit in diet data describes the percentage of time spent feeding/foraging on fruit based on observational data. Nuts, seeds, and seed pods are typically high value, patchily distributed and contestable in the same way as fruits and so were also included in this category. We obtained some data from sources using different but equivalent methods and calculated the percentage time spent feeding/foraging on fruit from these data, e.g., where data were given as relative frequencies. Equivalent methods are those based on 


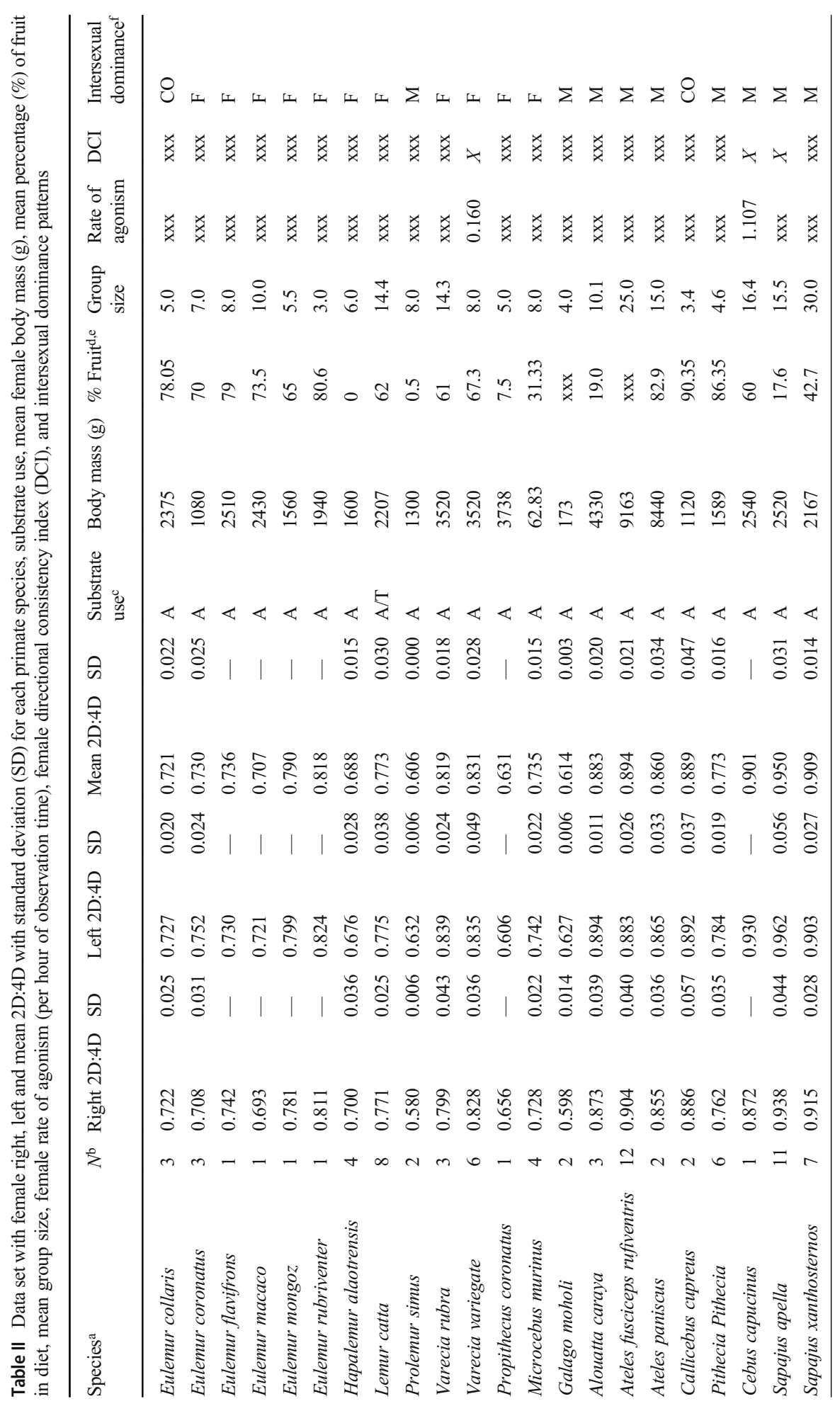




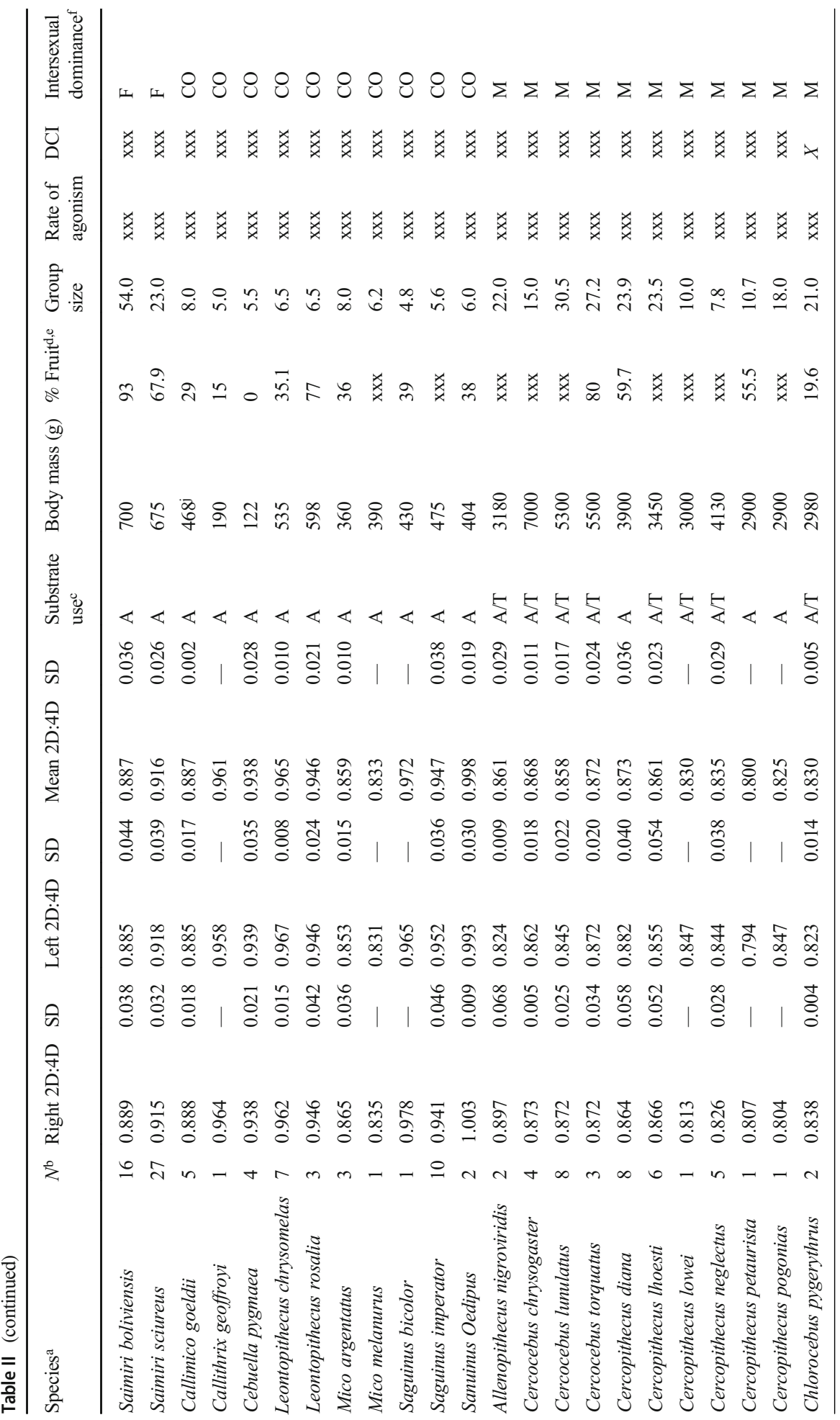




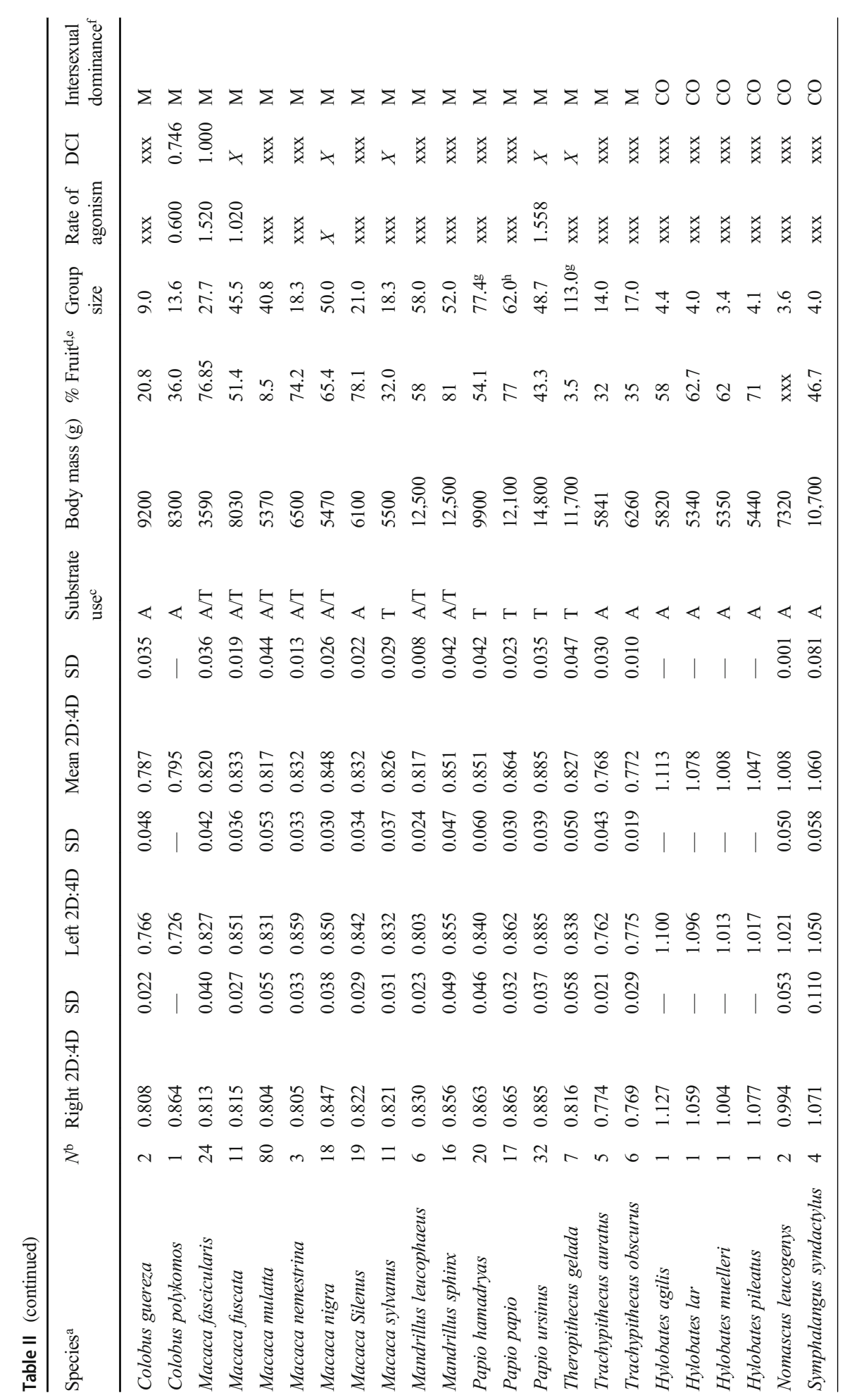




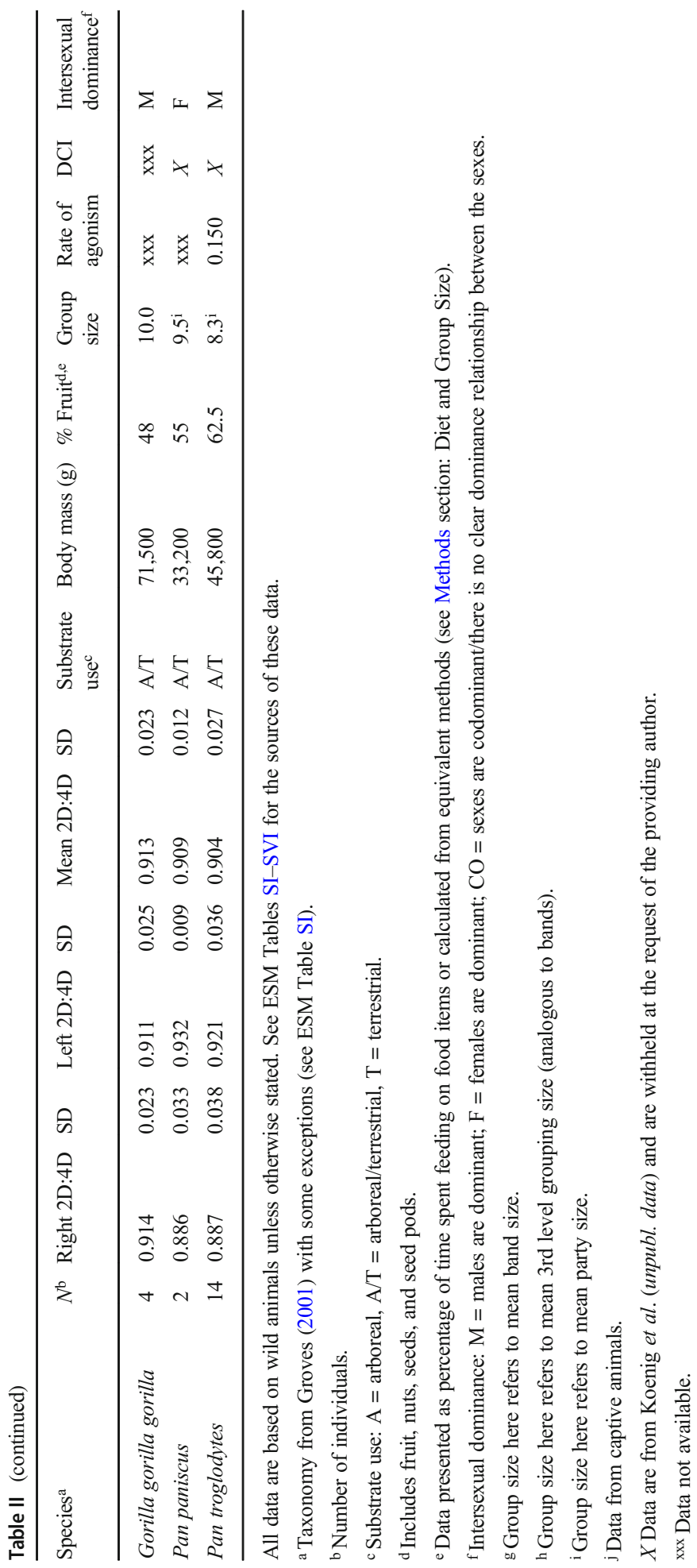


scan sampling, where the interval between samples is short relative to the mean duration of the behavior. This method provides estimates of time spent feeding on food items (Martin and Bateson 2007), as do methods in which dietary intake is determined through the proportion of all scan samples in which a food item was recorded as being fed upon (Davies et al. 1999).

We obtained data on mean species group size (includes both sexes and all age classes) from the literature. If more than one value was available for a species (e.g., representing different populations), we took the mean of these as the mean group size value for the species as a whole. Where data described the size of mixed-species groups, we included only the number of individuals of the species in question. For some species that live in large multilevel groups, mean group size data describes smaller grouping levels, e.g., band level of social structure in Papio hamadryas (Table II; ESM Table SIV).

\section{Female Social Variables}

We collated data on DCI and rate of agonism from the literature. DCI describes the proportion of interactions in the more common direction in each dyad (i.e., when the outcome of an agonistic encounter is in favor of the individual in the dyad who most often wins) among females in a social group. It is calculated by subtracting the number of interactions in the rarer direction from those in the more common direction, divided by the total number of interactions. DCI varies on a scale from 0 to 1 (low to high) with a DCI value of 1 , meaning there is complete unidirectionality in the outcome of dominant/agonistic interactions across all dyads (van Hooff and Wensing 1987). We also obtained data on rates of agonism per hour of observation time (rate of agonism). This was based on data collected through continuous focal sampling of known females. If more than one value was available for a species (representing different groups/ populations), we used the mean of these as the DCI and rate of agonism values for the species as a whole. Data on DCI and rates of agonism were available for 13 and 8 species in the 2D:4D ratio data set respectively (Table II; ESM Table SV).

\section{Mating System Variables}

We collated data from various sources on mating system and mating system subcategory for each species (ESM Table SVI). Categories for mating system are monogamy, polyandry, polygyny, and polygynandry. Polygynous and polygynandrous mating systems were then broken down into further subcategories depending on the form in which these systems present in each species (ESM Table SVII; Howlett and Wheeler unpubl. data). As primate mating systems and group size are linked, such that monogamous species often live in smaller groups while the largest groups tend to be associated with polygynandry, we also controlled for group size in the mating system analyses to ensure that any relationships between mating variables and 2D:4D ratios are not a consequence of group size effects.

\section{Intersexual Dominance Patterns}

We obtained data on intersexual dominance patterns for all 71 species in the data set from the literature (Table II; ESM Table SVIII). We categorized species as female 
dominant, male dominant, or codominant. Female dominant species are those in which females are consistently able to dominate and/or receive submissive signals from their male counterparts without reversals in these roles. Male dominant describes species that display the opposite condition. Codominant describes those species in which there is no clear dominance pattern between the sexes or where an alpha male and female pair are codominant over other group members of both sexes.

\section{Statistical Methods}

We used Shapiro-Wilk tests throughout when assessing normality of the data. Data for female R2D:4D, L2D:4D, and M2D:4D were normally distributed, as were percentage fruit in diet and rate of agonism. Female body mass and group size were not normally distributed and so these variables were log-transformed. DCI data were also not normally distributed and were arcsine transformed. All other variables are categorical. We tested for multicollinearity of the predictor variables in each analysis using the variance inflation factor (VIF). Variance inflation factors (VIF) of between 1 and 1.344 were obtained indicating there is no evidence for multicollinearity among the independent variables.

\section{D:4D Ratio Measurement Reliability}

We used the single measures values of the intraclass correlation coefficient (ICC) set to the 'absolute agreement' definition to test intraobserver reliability. ICC values showed that 2D:4D ratio measurements were highly repeatable for both hands (for R2D:4DICC $=0.992, F_{512,7168}=1891.487, P=<0.001$; for L2D:4D ICC $=0.992, F_{512,7168}=$ 1774.794, $P=<0.001)$. We investigated differences in female R2D:4D and L2D:4D using a paired $t$-test (two-tailed). R2D:4D and L2D:4D in females were not significantly different $\left(t_{70}=-0.754, P=0.435\right)$ and were tightly correlated (Pearson correlation: $r=0.954, \mathrm{df}=71, P=<0.001)$; therefore we also used M2D:4D in subsequent analyses.

\section{Phylogenetic Signal}

We tested for phylogenetic signal using Pagel's $\lambda$ and the packages Devtools and Models of Trait Macroevolution on Trees (motmot) in the statistical software program $\mathrm{R}$ version 3.4.1 "Single candle" and 10kTrees (version 3) phylogeny with associated taxonomy from GenBank for the phylogenetic trees (Arnold et al. 2010). We found statistically significant Pagel's $\lambda$ values for all variables other than percentage of fruit in diet, DCI, and rate of agonism (Table III). Since 2D:4D ratio measures had significant amounts of phylogenetic signal, the use of phylogenetically controlled methods is appropriate.

\section{Phylogenetically Controlled Analysis}

The 2D:4D ratio is a proposed proxy for PAEs, which in turn are likely modulated by the social and ecological environment. Therefore, in all analyses, we assigned 2D:4D ratio measures as the dependent variables and all other variables as the independent 
Table III Phylogenetic signal results using Pagel's $\lambda$ for each variable in female primates

\begin{tabular}{|c|c|c|c|c|}
\hline Variable & $\Lambda$ & $\log L^{a}$ & $P$ & $N^{\mathrm{b}}$ \\
\hline Female R2D:4D & 1.000 & 108.455 & $<0.001$ & 71 \\
\hline Female L2D:4D & 0.988 & 109.936 & $<0.001$ & 71 \\
\hline Female M2D:4D & 0.997 & 114.575 & $<0.001$ & 71 \\
\hline Female body mass & 1.000 & -58.003 & $<0.001$ & 71 \\
\hline Substrate use & 1.000 & -32.096 & $<0.001$ & 71 \\
\hline Mating system & 1.000 & -99.634 & $<0.001$ & 71 \\
\hline Mating system subcategory & 1.000 & -128.191 & $<0.001$ & 71 \\
\hline Intersexual dominance & 0.890 & -56.050 & $<0.001$ & 71 \\
\hline Group size & 0.964 & -59.644 & $<0.001$ & 71 \\
\hline Percentage fruit & 0.000 & -274.837 & 1.000 & 71 \\
\hline DCI & 0.000 & 1.775 & 1.000 & 13 \\
\hline Rate of agonism & 0.000 & -5.995 & 1.000 & 8 \\
\hline
\end{tabular}

${ }^{a}$ Log-likelihood ratio statistic.

${ }^{\mathrm{b}}$ Number of species.

variables. To test for relationships between female 2D:4D ratios and the variables of interest (substrate use, female body mass, percentage of fruit in diet, group size, DCI, rate of agonism, mating system, mating system subcategory, and intersexual dominance pattern), we carried out phylogenetic generalized least squares (PGLS) analysis using the package Comparative Analysis of Phylogenetics and Evolution in R (caper). We ran the analysis across a block of 200 phylogenetic trees for each variable. Molecular data were not available for five species in the 10KTrees phylogeny (Callicebus cupreus, Mico melanurus, Cercocebus chrysogaster, Cercocebus lunulatus, and Propithecus coronatus) and so, using the R package Analysis of Phylogenetics and Evolution (ape), we added these species into the trees based on their relationships to sister taxa that were present in 10Ktrees phylogeny. Callicebus moloch and Callicebus cupreus are sister species that diverged ca. 3.65 mya (Byrne et al. 2016; Perelman et al. 2011). Mico melanurus is in the Mico subgenus and we included it using information on phylogeny from Garbino (2015). We included Cercocebus chrysogaster using Cercocebus torquatus, from which it diverged ca. 3.33 mya. We included Cercocebus lunulatus using its sister species, the Sooty mangabey (C. torquatus atys). C. lunulatus was widely considered a subspecies of $C$. $t$. atys (Groves 2001) until recent taxonomic reassessment elevated it to species level (Mittermeier et al. 2013; Oates et al. 2016). Genetic data suggest that P. coronatus and $P$. deckenii are the same subspecies and so we substituted $P$. deckenii for $P$. coronatus in the phylogeny (Pastorini et al. 2001; cf. Thalmann et al. 2002).

\section{Ethical Note}

This research was supported by the British and Irish Association of Zoos and Aquariums and all hand images were collected with the permission of the institutions involved. Our method of obtaining digit measurements through digital photographs is noninvasive and 
Perpex® images were collected only opportunistically when individuals were undergoing veterinary care. The authors declare that they have no conflict of interest.

Data Availability All data used in this study are available in the Electronic Supplementary Material (Tables SI-SVIII).

\section{Results}

\section{Anatomical Considerations}

There were no significant relationships between female body mass or substrate use and any of the 2D:4D ratio measures (Table IV). However, due to the variation in hand morphology and allometry that exists between species, female body mass and substrate use were included as factors in all analyses.

\section{Other Control Variables}

Both mating variables were significantly related to group size (Table V) and so group size was also included as an additional factor in analysis on mating systems.

\section{Diet and Group Size}

There were no significant associations between the percentage fruit in diet or group size and any of the 2D:4D ratio measures (Table VI).

\section{Female Social Variables}

There were no significant associations between either DCI (Fig. 2) or rate of agonism and any of the 2D:4D ratio measures (Table VII).

\section{Mating System Variables}

There were significant associations between mating system and all female R2D:4D and M2D:4D but not L2D:4D (Table VIII; Fig. 3). There were also significant associations

Table IV Results of a PGLS regression testing for an effect of substrate use and female body mass on female $2 \mathrm{D}: 4 \mathrm{D}$ ratio in primates

\begin{tabular}{llllllll}
\hline Variables & $\mathrm{t}$ & $\mathrm{P}$ & Estimate & $\mathrm{SE}$ & $\mathrm{df}$ & $\lambda$ & Adj. $^{2}$ \\
\hline Female R2D:4D and substrate use & 0.477 & 0.635 & 0.395 & 0.834 & 66 & 0.993 & -0.011 \\
Female L2D:4D and substrate use & 0.709 & 0.481 & 0.580 & 0.817 & 66 & 0.963 & -0.007 \\
Female M2D:4D and substrate use & 0.638 & 0.526 & 0.533 & 0.834 & 66 & 0.963 & -0.009 \\
Female R2D:4D and female body mass & -0.117 & 0.894 & -0.169 & 1.442 & 66 & 1.000 & -0.016 \\
Female L2D:4D and female body mass & -0.481 & 0.630 & -0.744 & 1.536 & 66 & 1.000 & -0.013 \\
Female M2D:4D and female body mass & -0.321 & 0.742 & -0.505 & 1.561 & 66 & 1.000 & -0.015 \\
\hline
\end{tabular}


Table V Results of the PGLS regression testing for an effect of group size on mating system and mating system subcategory in female primates while controlling for substrate use and female body mass

\begin{tabular}{llllllll}
\hline Variables & $\mathrm{t}$ & $\mathrm{P}$ & Estimate & $\mathrm{SE}$ & $\mathrm{df}$ & $\Lambda$ & Adj. $^{2}$ \\
\hline Mating system and group size & 3.050 & $\underline{0.003}$ & 0.198 & 0.065 & 66 & 0.880 & 0.164 \\
Substrate use & 1.301 & 0.198 & 0.207 & 0.158 & & & \\
Body mass & 1.366 & 0.176 & 0.109 & 0.081 & & & \\
Mating system subcategory and group size & 3.936 & $\underline{<0.001}$ & 0.131 & 0.033 & 66 & 0.808 & 0.249 \\
Substrate use & 1.709 & 0.093 & 0.261 & 0.152 & & & \\
Body mass & 0.571 & 0.570 & 0.044 & 0.077 & & & \\
\hline
\end{tabular}

Model variables are indicated in bold with the control variables taken into account; parameters for individual control variables are displayed below these. Significant results are underlined.

between mating system subcategory and female R2D:4D and M2D:4D but not L2D:4D (Table VIII; Fig. 4).

\section{Intersexual Dominance Relationships}

There were significant relationships between all 2D:4D ratio measures and intersexual dominance pattern (Table IX). Species in which females are the dominant sex had lower female R2D:4D, L2D:4D and M2D:4D, followed by females in male dominated species with females in codominant species having the highest 2D:4D ratios (Fig. 5).

Table VI Results of a PGLS regression testing for an effect of percentage (\%) of fruit in diet and mean group size on female primate $2 \mathrm{D}: 4 \mathrm{D}$ ratio while controlling for substrate use and female body mass

\begin{tabular}{|c|c|c|c|c|c|c|c|}
\hline Variables & $\mathrm{T}$ & $\mathrm{P}$ & Estimate & SE & $\mathrm{df}$ & $\lambda$ & Adj. $\mathrm{r}^{2}$ \\
\hline Female R2D:4D and \% fruit in diet & 1.402 & 0.166 & 75.591 & 53.744 & \multirow[t]{3}{*}{55} & \multirow[t]{3}{*}{0.813} & \multirow[t]{3}{*}{0.004} \\
\hline Substrate use & -0.958 & 0.342 & -8.107 & 8.440 & & & \\
\hline Body mass & 0.934 & 0.354 & 2.812 & 4.089 & & & \\
\hline Female L2D:4D and \% fruit in diet & 1.665 & 0.102 & 87.695 & 52.891 & \multirow[t]{3}{*}{55} & \multirow[t]{3}{*}{0.752} & \multirow[t]{3}{*}{0.018} \\
\hline Substrate use & -1.037 & 0.304 & -8.568 & 8.238 & & & \\
\hline Body mass & 1.048 & 0.299 & 4.113 & 3.934 & & & \\
\hline Female M2D:4D and \% fruit in diet & 1.548 & 0.127 & 85.394 & 54.986 & \multirow[t]{3}{*}{55} & \multirow[t]{3}{*}{0.786} & \multirow[t]{3}{*}{0.012} \\
\hline Substrate use & -1.000 & 0.322 & -8.362 & 8.343 & & & \\
\hline Body mass & 0.996 & 0.323 & 3.991 & 4.013 & & & \\
\hline Female R2D:4D and group size & -0.375 & 0.709 & -0.422 & 1.125 & \multirow[t]{3}{*}{67} & \multirow[t]{3}{*}{0.952} & \multirow[t]{3}{*}{0.014} \\
\hline Substrate use & 0.987 & 0.328 & 0.183 & 0.185 & & & \\
\hline Body mass & 1.474 & 0.145 & 0.135 & 0.092 & & & \\
\hline Female L2D:4D and group size & -0.677 & 0.501 & -0.806 & 1.189 & \multirow[t]{3}{*}{67} & \multirow[t]{3}{*}{0.957} & \multirow[t]{3}{*}{0.016} \\
\hline Substrate use & 0.975 & 0.335 & 0.181 & 0.185 & & & \\
\hline Body mass & 1.434 & 0.157 & 0.132 & 0.092 & & & \\
\hline Female M2D:4D and group size & -0.550 & 0.584 & -0.666 & 1.215 & \multirow[t]{3}{*}{67} & \multirow[t]{3}{*}{0.954} & \multirow[t]{3}{*}{0.015} \\
\hline Substrate use & 0.993 & 0.325 & 0.185 & 0.185 & & & \\
\hline Body mass & 1.458 & 0.150 & 0.134 & 0.092 & & & \\
\hline
\end{tabular}

Model variables are indicated in bold with the control variables taken into account; parameters for individual control variables are displayed below these 


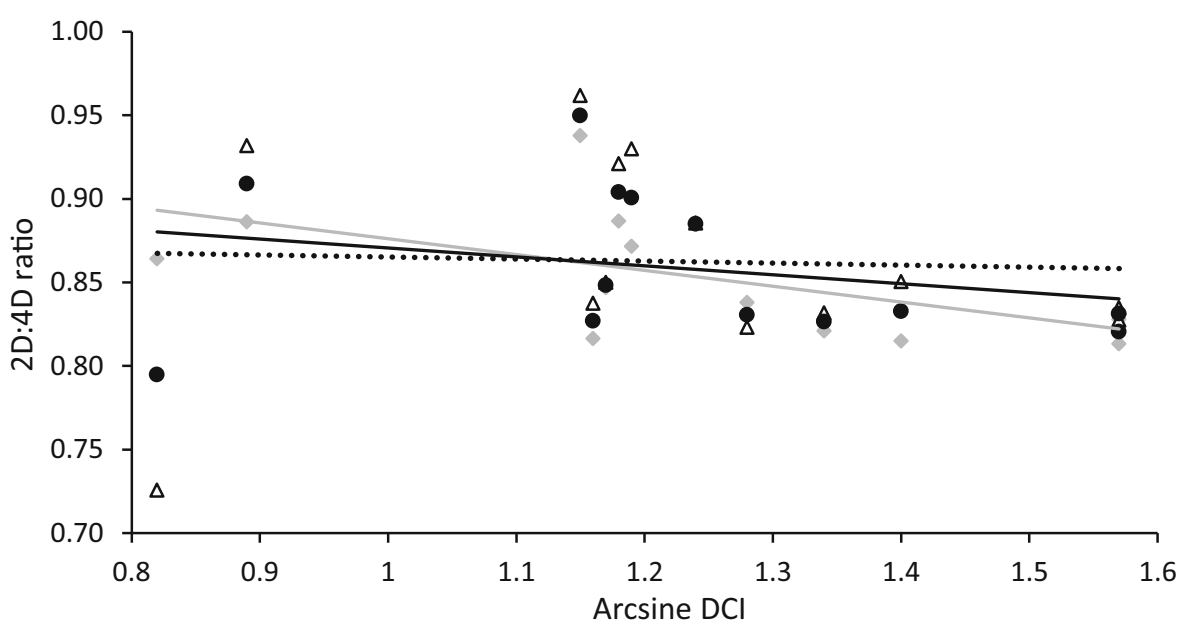

Fig. 2 Association between arcsine dominance consistency index (DCI) and female primate 2D:4D ratio measures. Right 2D:4D, gray diamonds, gray solid trendline; left 2D:4D, white triangles, black dotted trendline; mean, 2D:4D, black circles, black solid trendline.

\section{Discussion}

The support for variation in primate socioecology being underpinned by variation in PAEs was mixed. Predictions regarding the relationship between PAEs and female reproductive competition and intersexual dominance patterns were met. However, we

Table VII Results of a PGLS regression testing for an effect of female primate DCI and rate of agonism on female 2D:4D ratio while controlling for substrate use and female body mass

\begin{tabular}{llllllll}
\hline Variables & $\mathrm{t}$ & $\mathrm{P}$ & Estimate & $\mathrm{SE}$ & $\mathrm{df}$ & $\lambda$ & Adj. $^{2}$ \\
\hline Female R2:D4D and DCI & -1.699 & 0.130 & -2.896 & 1.700 & 9 & 0.078 & 0.238 \\
Substrate use & 0.113 & 0.912 & 0.012 & 0.104 & & & \\
Body mass & -1.184 & 0.266 & -0.082 & 0.068 & & & 0.074 \\
Female L2D:4D and DCI & 0.361 & 0.729 & 0.423 & 1.162 & 9 & 0.634 & \\
Substrate use & 0.820 & 0.433 & 0.096 & 0.120 & & & \\
Body mass & -1.398 & 0.197 & -0.115 & 0.084 & & & -0.056 \\
Female M2D:4D and DCI & -0.271 & 0.776 & -0.431 & 1.600 & 9 & 0.540 & \\
Substrate use & 0.896 & 0.396 & 0.101 & 0.114 & & & \\
Body mass & -1.336 & 0.216 & -0.109 & 0.081 & & & 0.544 \\
Female R2D:4D and rate of agonism & 1.132 & 0.320 & 6.773 & 5.980 & 4 & 0.000 & \\
Substrate use & 3.161 & 0.034 & 0.774 & 0.244 & & & \\
Body mass & -2.680 & 0.055 & -0.520 & 0.194 & & & 0.399 \\
Female L2D:4D and rate of agonism & 0.006 & 0.952 & 0.016 & 2.658 & 4 & 0.491 & \\
Substrate use & 2.340 & 0.081 & 0.689 & 0.284 & & \\
Body mass & -2.370 & 0.078 & -0.419 & 0.177 & & \\
Female M2D:4D and rate of agonism & 0.224 & 0.835 & 0.930 & 4.177 & 4 & 0.217 & 0.450 \\
Substrate use & 2.593 & 0.061 & 0.675 & 0.265 & & \\
Body mass & -2.349 & 0.079 & -0.417 & 0.174 & & \\
\hline
\end{tabular}

Model variables are indicated in bold with the control variables taken into account; parameters for individual control variables are displayed below these. Significant results are underlined. 
Table VIII Results of a PGLS regression testing for an effect of mating system variables on female primate 2D:4D ratio while controlling for substrate use, female body mass, and mean group size

\begin{tabular}{|c|c|c|c|c|c|c|c|}
\hline Variables & $\mathrm{T}$ & $\mathrm{P}$ & Estimate & SE & df & $\lambda$ & Adj. $\mathrm{r}^{2}$ \\
\hline Female R2D:4D and mating system & -2.650 & 0.010 & -4.773 & 1.794 & \multirow[t]{4}{*}{66} & \multirow[t]{4}{*}{1.000} & \multirow[t]{4}{*}{0.143} \\
\hline Substrate use & 1.118 & 0.268 & 0.296 & 0.265 & & & \\
\hline Body mass & 0.286 & 0.775 & 0.045 & 0.155 & & & \\
\hline Group size & 2.423 & 0.018 & 0.460 & 0.192 & & & \\
\hline Female L2D:4D and mating system & -1.836 & $\overline{0.072}$ & -3.610 & 1.972 & \multirow[t]{4}{*}{66} & \multirow[t]{4}{*}{1.000} & \multirow[t]{4}{*}{0.098} \\
\hline Substrate use & 1.108 & 0.272 & 0.302 & 0.272 & & & \\
\hline Body mass & 0.218 & 0.824 & 0.035 & 0.161 & & & \\
\hline Groups size & 2.278 & 0.026 & 0.445 & 0.195 & & & \\
\hline Female M2D:4D and mating system & -2.436 & 0.018 & -4.810 & 1.977 & \multirow[t]{4}{*}{66} & \multirow[t]{4}{*}{1.000} & \multirow[t]{4}{*}{0.130} \\
\hline Substrate use & 1.153 & $\overline{0.253}$ & 0.308 & 0.272 & & & \\
\hline Body mass & 0.236 & 0.811 & 0.037 & 0.157 & & & \\
\hline Group size & 2.327 & 0.023 & 0.446 & 0.193 & & & \\
\hline Female R2D:4D and mating system subcategory & -2.970 & 0.006 & -8.328 & 3.305 & \multirow[t]{4}{*}{65} & \multirow[t]{4}{*}{0.687} & \multirow[t]{4}{*}{0.363} \\
\hline Substrate use & 1.019 & $\overline{0.742}$ & 0.040 & 0.484 & & & \\
\hline Body mass & 2.447 & 0.033 & 0.534 & 0.227 & & & \\
\hline Group size & 4.313 & $\overline{<0.001}$ & 1.448 & 0.343 & & & \\
\hline Female L2D:4D and mating system subcategory & -1.898 & 0.062 & -6.148 & 3.182 & \multirow[t]{4}{*}{65} & \multirow[t]{4}{*}{0.789} & \multirow[t]{4}{*}{0.284} \\
\hline Substrate use & 0.315 & 0.759 & 0.160 & 0.510 & & & \\
\hline Body mass & 2.005 & 0.054 & 0.484 & 0.243 & & & \\
\hline Group size & 3.887 & $<0.001$ & 1.399 & 0.360 & & & \\
\hline Female M2D:4D and mating system subcategory & -2.458 & 0.017 & -7.911 & 3.190 & \multirow[t]{4}{*}{65} & \multirow[t]{4}{*}{0.777} & \multirow[t]{4}{*}{0.314} \\
\hline Substrate use & 0.289 & $\overline{0.780}$ & 0.144 & 0.496 & & & \\
\hline Body mass & 2.129 & 0.042 & 0.501 & 0.236 & & & \\
\hline Group size & 3.968 & $\overline{<0.001}$ & 1.399 & 0.351 & & & \\
\hline
\end{tabular}

Model variables are indicated in bold with the control variables taken into account; parameters for individual control variables are displayed below these. Significant results are underlined.

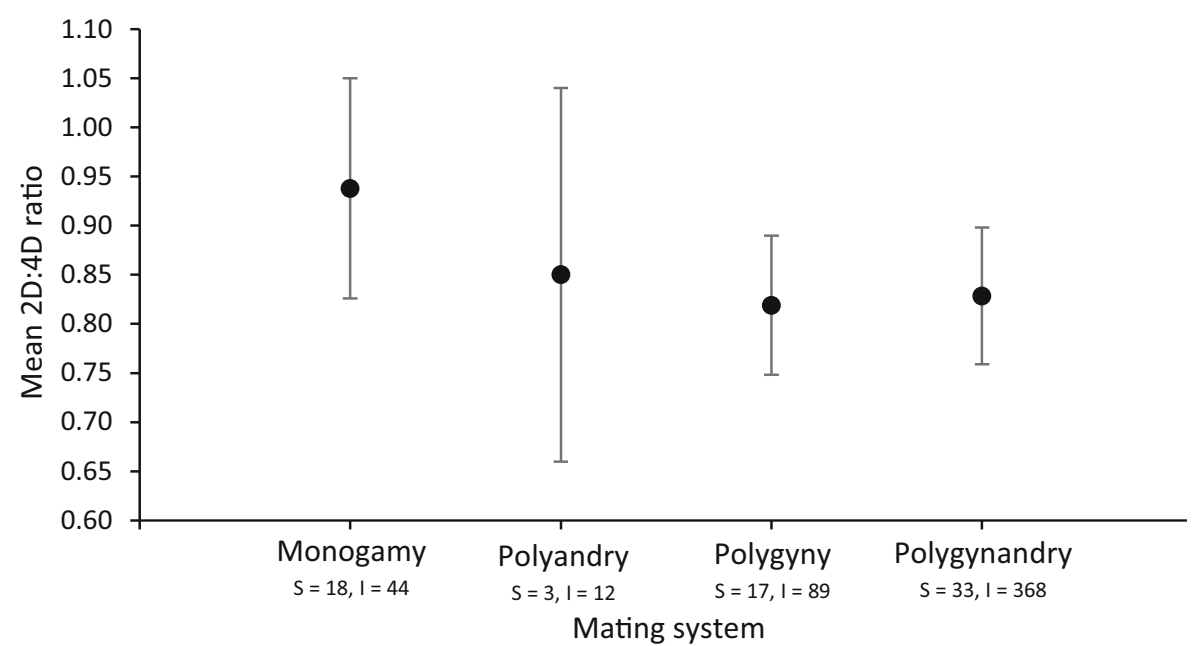

Fig. 3 Relationship between female primate mean 2D:4D (group mean \pm standard deviation) and species mating system. Number of species (S) and number of individuals (I) included in each category are given below the mating system. 


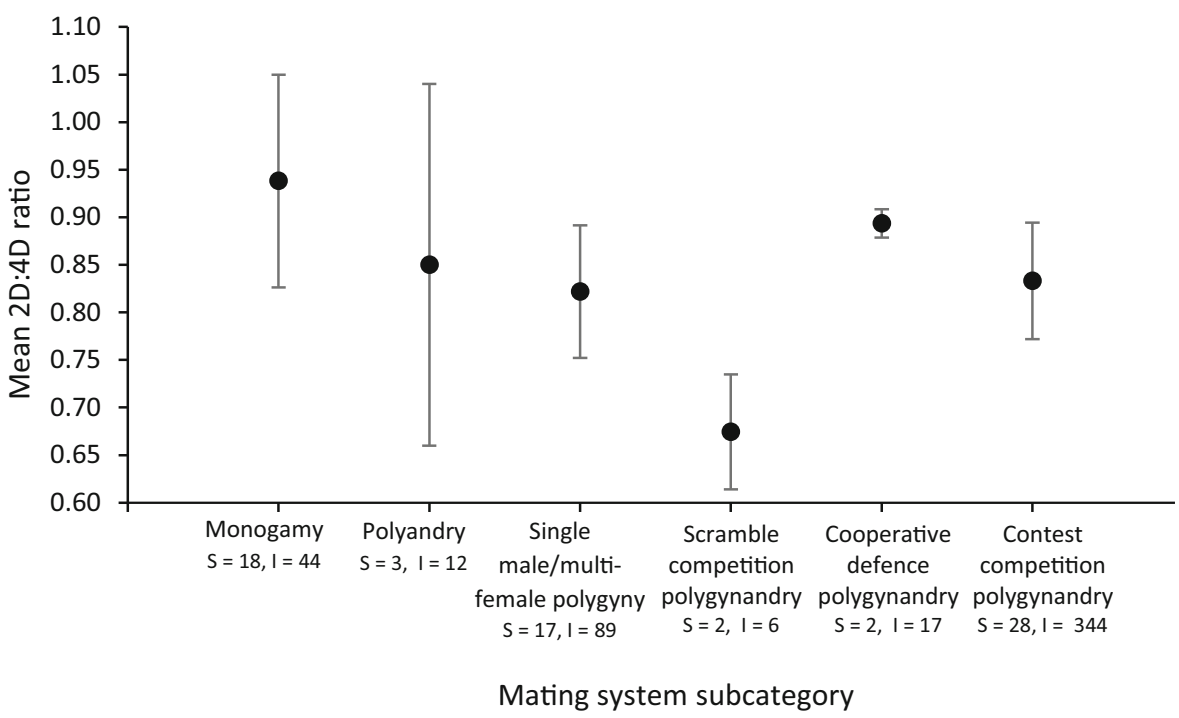

Fig. 4 Relationship between female primate mean 2D:4D ratio (group mean \pm standard deviation) and mating system subcategory. Number of species (S) and number of individuals (I) included in each category are given below the mating system subcategory.

did not find the expected relationships between PAEs and degree of frugivory, group size, or the two quantitative measures of female dominance behavior. This study demonstrates that PAEs may act as a proximate mechanism underlying variation in certain aspects of social behavior in female nonhuman primates but may not be associated with the (potential) effects of diet and group size on social structure. Alternatively, these two factors that are often used to formulate the hypotheses on which classic socioecological theory is based may not, in fact, be reliable predictors of female intrasexual competition levels.

As predicted, monogamous females had the highest 2D:4D ratios, likely as a result of selection for many of the key behaviors underpinning monogamous relationships in primates (e.g., pair bonding and parental care) also requiring selection for reduced

Table IX Results of a PGLS regression testing for an effect of intersexual dominance relationships on female primate 2D:4D ratio while controlling for substrate use and female body mass

\begin{tabular}{llllllll}
\hline Variables & $\mathrm{T}$ & $\mathrm{P}$ & Estimate & $\mathrm{SE}$ & $\mathrm{df}$ & $\lambda$ & Adj.r $^{2}$ \\
\hline Female R2D:4D and intersexual dominance & 3.106 & $\underline{0.003}$ & 3.217 & 1.036 & 67 & 0.974 & 0.112 \\
Substrate use & 0.177 & 0.860 & 0.024 & 0.132 & & & \\
Body mass & 0.020 & 0.862 & 0.002 & 0.078 & & & \\
Female L2D:4D and intersexual dominance & 2.619 & $\underline{0.011}$ & 2.919 & 1.115 & 67 & 0.977 & 0.078 \\
Substrate use & 0.163 & 0.871 & 0.022 & 0.133 & & & \\
Body mass & -0.001 & 0.892 & $<0.000$ & $<0.000$ & & & \\
Female M2D:4D and intersexual dominance & 3.025 & 0.004 & 3.388 & 1.120 & 67 & 0.979 & 0.106 \\
Substrate use & 0.153 & 0.878 & 0.021 & 0.132 & & & \\
Body mass & 0.029 & 0.883 & 0.002 & 0.078 & & & \\
\hline
\end{tabular}

Model variables are indicated in bold with the control variables taken into account; parameters for individual control variables are displayed below these. Significant results are underlined. 


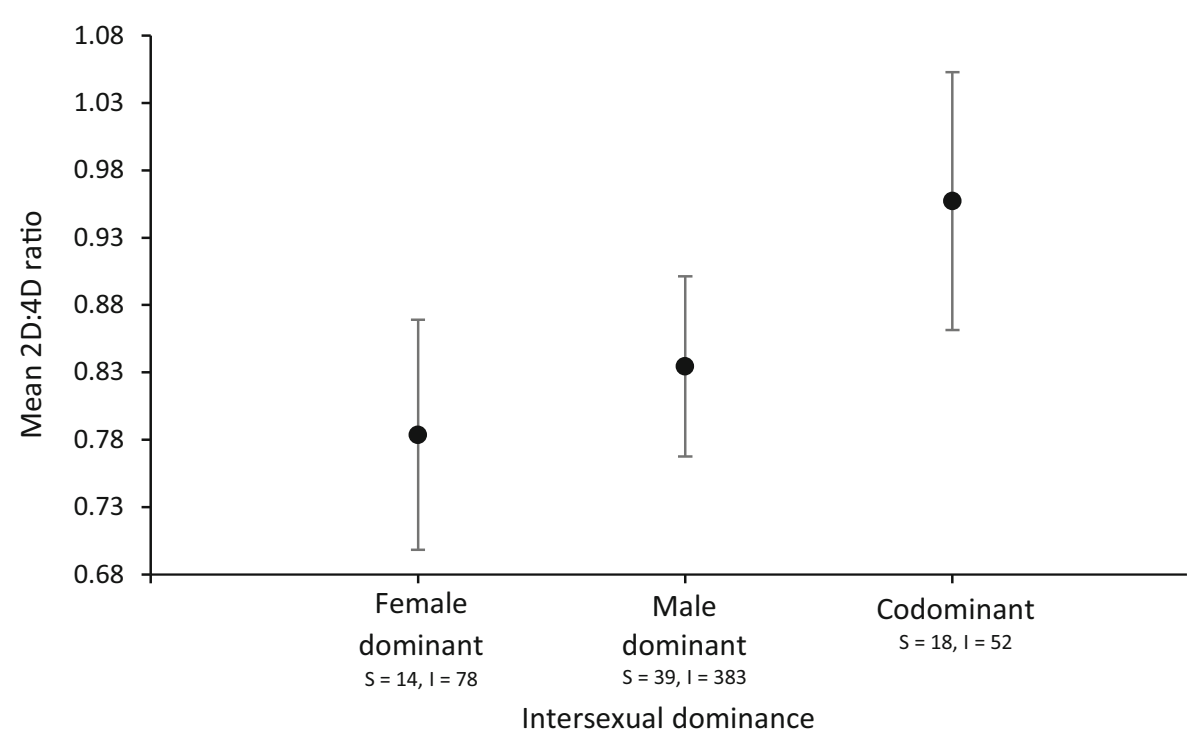

Fig. 5 Association between intersexual dominance patterns and female primate mean 2D:4D (group mean \pm standard deviation). Number of species (S) and number of individuals (I) included in each category are given below the intersexual dominance pattern.

PAEs and/or increased POEs (French et al. 2018). Polyandrous females had lower 2D:4D ratios than monogamous females but higher 2D:4D ratios than females characterized by polygyny or polygynandry. Females of species characterized by polygynous mating had the lowest $2 \mathrm{D}: 4 \mathrm{D}$ ratios, followed by polygynandrous females. It is not clear why 2D:4D ratios would differ in polygynous and polygynandrous female primates but the pattern may stem from differences in female relationships between the subcategories of the mating systems, if indeed these social differences place differential selective pressures in terms of PAEs. Females characterized by scramble competition polygynandry had the lowest $2 \mathrm{D}: 4 \mathrm{D}$ ratios but these values are based on two strepsirrhine species only and data from haplorhine females characterized by this mating system are needed before any conclusions can be made as to the relationship between PAEs and this mating system. Female 2D:4D ratios in species characterized by single male/multifemale polygyny and contest competition polygynandry were similar, with single male/multifemale polygyny $2 \mathrm{D}: 4 \mathrm{D}$ ratios being very slightly lower. This is perhaps unsurprising, as group formation in species characterized by these mating systems is likely to be very similar, meaning that females have similar competitive relationships with one another. Although small sample sizes precluded formal analysis, among polygynandrous species there was a tendency for female $2 \mathrm{D}: 4 \mathrm{D}$ ratios to be highest in species characterized by cooperative defence polygynandry. There is evidence that the formation of platonic social bonds is associated with OT in adult primates (Zeigler and Crockford 2017). The species characterized by cooperative defense polygyny in this study (Pan troglodytes and Alouatta caraya) are likely to experience increased selection for cooperative and affiliative behaviors (moderated by estrogen and its associated neuropeptides) and increased POEs/reduced PAEs, as females in these species disperse from their natal groups at maturity and need to form relationships with other (usually) unrelated females in the groups they migrate into. 
There was a significant relationship between female 2D:4D ratios and intersexual dominance patterns. Female 2D:4D ratios were lower in species characterized by female dominance than those characterized by both male dominance and codominance. The low 2D:4D ratios in species characterized by female dominance may be due to selection for higher PAEs that could result in the behavioral masculinization necessary for dominating males in these species (Dunham 2008). The results lend support to prenatal sex hormones acting as a proximate mechanism underlying the evolution of female dominance in nonhuman primates (Petty and Drea 2015). Codominant species have the highest 2D:4D ratios (lower PAEs) and this could be due to their mating systems, as species in which the sexes are codominant (e.g., gibbons, titi monkeys, marmosets, and tamarins) are often characterized by monogamy or polyandry (Carpenter 1940; Kinzey 1981; Koba et al. 2012).

There were no significant relationships between female 2D:4D ratios and either of the measures of female dominance behavior. Species that showed higher rates of female-female agonism did not have significantly lower 2D:4D ratios than those with lower rates. Likewise, the associations between DCI and the 2D:4D ratio measures were not significant, although a weak trend was discernible in the predicted direction (i.e., females with higher DCI tended to have lower 2D:4D ratios [higher inferred PAEs]), although this was limited to the right hand. As DCI is perhaps the most reliable way to quantify the degree of despotism characterizing a given primate group, this trend is consistent with previous studies that noted associations between levels of female intrasexual competition and 2D:4D ratios in anthropoid primates (Nelson and Shultz 2010). Quantitative measures of female dominance are better able to represent the variation we see in female social relationships across primates than the broad classifications of traditional socioecological models. However, sample sizes were small for both of these variables and so the lack of a significant relationship may result from a lack of statistical power. Further research into the relationship between quantitative female dominance measures and 2D:4D ratios with larger sample sizes could prove productive.

Contrary to our prediction, females with a higher percentage of fruit in their diet did not have lower 2D:4D ratios. The hypothesized greater contestability of fruit relative to other food types led to the suggestion that feeding competition should be greatest among highly frugivorous species and lowest among highly folivorous species (Clutton-Brock and Janson 2012; Snaith and Chapman 2007), which has been corroborated by some studies (Janson and Goldsmith 1995; Steenbeek and van Schaik 2001), but not others. For example, intragroup contest competition was not elevated by increased feeding on fruits in Macaca assamensis (Heesen et al. 2013) and no association was found between rates of agonism in female primates and the percentage of fruit in their diet (Wheeler et al. 2013). Folivorous species display a preference for young, tender leaves that can be patchily distributed and therefore contestable (Koenig et al. 1998; Yeager and Kool 2000). The fact that folivores may also experience high levels of contest competition is supported by the observation that female dominance relationships in a highly folivorous colobine monkey were substantially affected by occasionally feeding on seasonal high-quality, contestable foods (Wikberg et al. 2013). The results lend support to dietary categories (or degree of frugivory) not being good predictors of female intrasexual competition in primates. Other resources may be more important for some species, such as reproduction (French and Inglett 1989), and 
territory (Schülke and Kappeler 2003) and competition between females may occur in reference to these rather than just food. Although these findings were not significant in the Order-wide analysis, the relationship between PAEs and variables relating to competition for food may be apparent between individual females at the species level via the positive impact that PAEs have on an individual's competitive abilities and dominance rank (Hönekopp et al. 2006; Howlett et al. 2012). For example, in certain conditions, female primates with lower 2D:4D ratios (high PAEs) may be better able to outcompete intragroup rivals with higher 2D:4D ratios (lower PAEs) due to the behavioral predispositions brought about by high PAEs. This is supported by the link between dominance rank and resource acquisition in female primates including olive baboons (Papio anubis: Barton and Whiten 1993) and sooty mangabeys (Cercocebus torquatus atys: Range and Noë 2002).

Females of species characterized by larger group sizes did not have lower 2D:4D ratios than females of species that live in smaller groups. This is somewhat surprising as females living in larger groups have a greater number of intragroup competitors and an increased likelihood of experiencing contest competition (Koenig and Borries 2006) that can result in the higher rates of agonism that are observed among females living in larger groups (Wheeler et al. 2013). A possible explanation for the lack of relationship could be that intergroup competition in smaller primate groups, for example over territory in pair-living and solitary species, also generates selection for higher levels of PAEs, particularly in species where females are actively involved in territory defence (Anzenberger 1992; Raemaekers and Raemaekers 1985). Additionally, there is likely to be substantial selection for cooperative and affiliative behaviors to facilitate the coexistence of primates in large groups and this is likely to moderate selection for higher PAEs (French et al. 2018). Further, depending on relationships between females, larger group sizes could result in increased intragroup scramble competition and, unlike direct contest competition, scramble competition is not likely to result in increased selection for behaviors associated with higher PAEs (e.g., dominance), although there is evidence to suggest that intragroup contest competition also increases with increasing group size (Koenig and Borries 2006; Wheeler et al. 2013). This, together with the fact that dietary composition and group size cannot fully predict female intrasexual competition within and between groups, likely explains the lack of a relationship between these variables and PAEs.

The hormones underlying competitive and cooperative behaviors are largely conserved across all mammals (Soares et al. 2010; Trumble et al. 2015) and PAEs may act as a proximate mechanism underlying the expression of certain aspects of behavior in female primates in ways that are adaptive to their social system. The results stress that, to fully understand the relationship between PAEs and competition in female nonhuman primates, it is necessary to consider reproductive competition and intersexual dominance relationships alongside ecological factors and female sociality. The predictions of this study are based on the assumption that the $2 \mathrm{D}: 4 \mathrm{D}$ ratio is a negative correlate of PAEs across primate species, such that lower 2D:4D ratios indicate higher PAEs and higher 2D:4D ratios indicate lower PAEs. However, because some studies have observed species in which males have on average higher 2D:4D ratios (lower inferred PAEs) than females (Baxter et al. 2018; Roney et al. 2004) this suggests that the pattern may not be universal across the Order and in some species for example, higher 2D:4D ratios may indicate higher PAEs. Such reversals in the pattern would bias 
against our predictions, and this, and not a lack of PAEs, may explain nonsignificant results. However, the fact that tests based on the broader categories of mating systems and intersexual dominance patterns were significant suggests that the expected trend of lower 2D:4D ratios reflecting higher PAEs likely holds across most species in the data set. Additional research into species specific patterns in 2D:4D ratio with consistent, reliable, and comparable measurement methods is needed to investigate this further.

Supplementary Information The online version contains supplementary material available at https://doi.org/ 10.1007/s10764-021-00204-8.

Acknowledgments Funding for this study was provided by a University of Kent 50th Anniversary $\mathrm{PhD}$ scholarship. We would like to thank the following institutions for supporting the study: Africa Alive!, Apenheul Primate Park, Banham Zoo, Blair Drummond Safari Park, Centre for Animal Rehabilitation and Education (C.A.R.E), Chessington World of Adventures Resort, Chester Zoo, Colchester Zoo, Cotswolds Wildlife Park, Deutsches Primatenzentrum, Drusillas Zoo Park, Edinburgh Zoo, Fondazione Bioparco di Roma, Hamerton Zoo, Highland Wildlife Park, Howlett's Wild Animal Park, Knowsley Safari Park, Landau Zoo, London Zoo, Longleat Safari Park, Marwell Wildlife Park, Newquay Zoo, Oasis Park Fuerteventura, Paignton Zoo, Port Lympne Reserve, Shepreth Wildlife Park, South Lakes Safari Zoo, Twycross Zoo, Whipsnade Wildlife Park, and Yorkshire Wildlife Park.

Author contributions $\mathrm{CH}$ conceived and designed the study, conducted fieldwork, analyzed the data, and wrote the manuscript. BCW contributed to the conception and design of the study and provided editorial advice.

Open Access This article is licensed under a Creative Commons Attribution 4.0 International License, which permits use, sharing, adaptation, distribution and reproduction in any medium or format, as long as you give appropriate credit to the original author(s) and the source, provide a link to the Creative Commons licence, and indicate if changes were made. The images or other third party material in this article are included in the article's Creative Commons licence, unless indicated otherwise in a credit line to the material. If material is not included in the article's Creative Commons licence and your intended use is not permitted by statutory regulation or exceeds the permitted use, you will need to obtain permission directly from the copyright holder. To view a copy of this licence, visit http://creativecommons.org/licenses/by/4.0/.

\section{References}

Abbott, A. D., Colman, R. J., Tiefenthaler, R., Dumesic, D. A., \& Abbott, D. H. (2012). Early-to-mid gestation fetal testosterone increases right hand 2D:4D finger length ratio in polycystic ovary syndromelike monkeys. PLoS ONE, 7, e42372.

Allaway, H. C., Bloski, T. G., Pierson, R. A., \& Lujan, M. E. (2009). Digit ratios (2D:4D) determined by computer-assisted analysis are more reliable than those using physical measurements, photocopies and printed scans. American Journal of Human Biology, 21, 265-270.

Anzenberger, G. (1992). Monogamous social systems and paternity in primates. In R. D. Martin, A. F. Dixson, \& E. J. Wickings (Eds.), Paternity in primates: Genetic tests and theories (pp. 203-224). Basel: Karger.

Arnold, C., Matthews, L. J., \& Nunn, C. L. (2010). The 10kTrees website: a new online resource for primate phylogeny. Evolutionary Anthropology, 19, 114-118.

Balestri, M., Campera, M., Serra, V., Barresi, M., Ramanamanjato, J., \& Donati, G. (2014). Possible role of secondary compounds in determining feeding choices of collared brown lemur females (Eulemur collaris): Avoidance, self-medication or just availability? Lemur News, 18, 24-27.

Barton, R. A., \& Whiten, A. (1993). Feeding competition among female olive baboons, Papio anubis. Animal Behaviour, 46, 777-789. 
Baxter, A., Wood, E. K., Jarman, P., Cameron, A. N., Capitanio, J. P., \& Higley, J. D. (2018). Sex differences in rhesus monkeys' digit ratio (2D: 4D ratio) and its association with maternal social dominance rank. Frontiers in Behavioral Neuroscience, 12, 213.

Benderlioglu, Z., \& Nelson, R. J. (2004). Digit length ratios predict reactive aggression in women, but not in men. Hormones and Behavior, 46, 558-564.

Burley, N. T., \& Foster, V. S. (2004). Digit ratio varies with sex, egg order and strength of mate preference in zebra finches. Proceedings of the Royal Society of London B: Biological Sciences, 271, 239-244.

Byrne, H., Rylands, A. B., Carneiro, J. F., Lynch Alfaro, J. W., Bertuol, F., et al (2016). Phylogenetic relationships of the New World titi monkeys (Callicebus): First appraisal of taxonomy based on molecular evidence. Frontiers in Zoology, 13, 10-35.

Campbell, C. J., Fuentes, A., MacKinnon, K. C., Bearder, S. K., \& Stumpf, R. M. (2011). Primates in perspective (2nd ed.). Oxford: Oxford University Press.

Carpenter, C. R. (1940). A field study in Siam of the behavior and the social relations of the gibbon (Hylobates lar). Comparative Psychology Monographs, 16, 1e212.

Chapman, C. A., Wrangham, R. W., \& Chapman, L. J. (1995). Ecological constraints on group size: An analysis of spider monkey and chimpanzee subgroups. Behavioural Ecology and Sociobiology, 36, 5970.

Clutton-Brock, T. (2009). Sexual selection in females. Animal Behaviour, 77, 3-11.

Clutton-Brock, T., \& Huchard, E. (2013). Social competition and selection in males and females. Philosophical Transactions of the Royal Society B: Biological Sciences, 368, 20130074.

Clutton-Brock, T., \& Janson, C. (2012). Primate socioecology at the crossroads: Past, present, and future. Evolutionary Anthropology, 21, 136-150.

Clutton-Brock, T. H., \& Harvey, P. H. (1976). Evolutionary rules and primate societies. In P. P. G. Bateson \& R. A. Hinde (Eds.), Growing points in ethology (pp. 195-237). Cambridge: Cambridge University Press.

Cords, M. (2000). Agonistic and affiliative relationships in a blue monkey group. In P. F. Whitehead \& C. J. Jolly (Eds.), Old World monkeys (pp. 453-479). Cambridge: Cambridge University Press.

Cowl, V. B., \& Shultz, S. (2017). Large brains and groups associated with high rates of agonism in primates. Behavioural Ecology, 28, 803-810.

Davies, A. G., Oates, J. F., \& Dasilva, G. L. (1999). Patterns of frugivory in three West African colobine monkeys. International Journal of Primatology, 20, 327-357.

Dunham, A. E. (2008). Battle of the sexes: Cost asymmetry explains female dominance in lemurs. Animal Behaviour, 76, 1435-1439.

Eichmueller, P., Thorén, S., \& Radespiel, U. (2013). The lack of female dominance in golden-brown mouse lemurs suggests alternative routes in lemur social evolution. American Journal of Physical Anthropology, $150,158-164$.

Fink, B., Manning, J. T., Williams, J. H. G., \& Podmore-Nappin, C. (2007). The 2nd to 4th digit ratio and developmental psychopathology in school-ages children. Personality and Individual Differences, 42, 369-379.

Fisher, H. E., Rich, J., Island, H. D., \& Marchalik, D. (2010). The second to fourth digit ratio: A measure of two hormonally-based temperament dimensions. Personality and Individual Differences, 49, 773-777.

French, J. A., Cavanaugh, J., Mustoe, A. C., Carp, S. B., \& Womack, S. L. (2018). Social monogamy in nonhuman primates: Phylogeny, phenotype and physiology. The Journal of Sex Research, 55, 410-434.

French, J. A., \& Inglett, B. J. (1989). Female-female aggression and male indifference in response to unfamiliar intruders in lion tamarins. Animal Behaviour, 37, 487-497.

Galis, F., Ten Broek, C. M. A., van Dongen, S., \& Wijnaendts, L. C. D. (2010). Sexual dimorphism in the prenatal digit ratio (2D:4D). Archives of Sexual Behavior, 39, 57-62.

Garber, P. A. (1994). Phylogenetic approach to the study of tamarin and marmoset social systems. American Journal of Primatology, 34, 199-219.

Garbino, G. S. T. (2015). How many marmoset (Primates: Cebidae: Callitrichinae) genera are there? A phylogenetic analysis based on multiple morphological systems. Cladistics, 31, 652-678.

Goy, R. W., Bercovitch, F. B., \& McBrair, M. C. (1988). Behavioral masculinization is independent of genital masculinization in prenatally androgenized female rhesus macaques. Hormones and Behavior, 22, 552571.

Groves, C. P. (2001). Primate taxonomy. Washington and London: Smithsonian Institution Press.

Hart, E. (2018). Metacarpal ratio and its relation to sexual dimorphism in primates with different mating strategies. Master's thesis, Louisiana State University.

Heesen, M., Rogahn, S., Ostner, J., \& Schülke, O. (2013). Food abundance affects energy intake and reproduction in frugivorous female Assamese macaques. Behavioural Ecology and Sociobiology, 67, 1053-1066. 
Howlett, C., Marshall, A. R., \& Hughes, W. O. H. (2012). Digit ratios and dominance in female baboons (Papio hamadryas and Papio ursinus). International Journal of Primatology, 33, 1439-1452.

Howlett, C., Setchell, J. M., Hill, R. A., \& Barton, R. A. (2015). The 2D:4D digit ratio and social behaviour in wild female chacma baboons (Papio ursinus) in relation to dominance, aggression, interest in infants, affiliation and heritability. Behavioural Ecology and Sociobiology, 69, 61-74.

Huchard, E., \& Cowlishaw, G. (2011). Female-female aggression around mating: An extra cost of sociality in a multimale primate society. Behavioural Ecology, 22, 1003-1011.

Hurd, P. L., Vaillancourt, K. L., \& Dinsdale, N. L. (2011). Aggression, digit ratio and variation in androgen receptor and monoamine oxidase A genes in men. Behavioural Genetics, 41, 543-556.

Isbell, L. A. (1991). Contest and scramble competition: Patterns of female aggression and ranging behavior among primates. Behavioural Ecology, 2, 143-154.

Isbell, L. A. (2004). Is there no place like home? Ecological bases of female dispersal and philopatry and their consequences for the formation of kin groups. In B. Chapais \& C. M. Berman (Eds.), Kinship and behavior in primates (pp. 71-108). Oxford: Oxford University Press.

Janson, C. (1985). Aggressive competition and individual food consumption in wild brown capuchin monkeys (Cebus apella). Behavioral Ecology and Sociobiology, 18, 125-138.

Janson, C. H., \& Goldsmith, M. L. (1995). Predicting group size in primates: Foraging costs and predation risks. Behavioural Ecology, 6, 326-336.

Janson, C. H., \& Van Schaik, C. P. (1988). Recognizing the many faces of primate food competition: Methods. Behaviour, 105, 165-186.

Johannes Hönekopp, J., Manning, J. T., \& Müller, C. (2006). Digit ratio (2D:4D) and physical fitness in males and females: Evidence for effects of prenatal androgens on sexually selected traits. Hormones and Behavior, 49, 545-549.

Jouffroy, F. K., Godinot, M., \& Nakano, Y. (1993). Biometrical characteristics of primate hands. In H. Preuschoft \& D. J. Chivers (Eds.), Hands of primates (pp. 133-172). Wien: Springer-Verlag.

Kappeler, P. M. (1991). Patterns of sexual dimorphism in body-weight among prosimian primates. Folia Primatologica, 57, 132-146.

Kappeler, P. M. (1993). Variation in social-structured the effects of sex and kinship on social interactions in three lemur species. Ethology, 93, 125-145.

Kappeler, P. M., \& van Schaik, C. P. (2002). Evolution of primate social systems. International Journal of Primatology, 23, 707-740.

Kemper, C. J., \& Schwerdtfeger, A. (2009). Comparing indirect methods of digit ratio (2D: 4D) measurement. American Journal of Human Biology, 21, 188-191.

Kinzey, W. G. (1981). The titi monkeys, genus Callicebus: I. Description of the species. In A. F. CoimbraFilho \& R. A. Mittermeier (Eds.), Ecology and behavior of neotropical primates, Vol. 1 (pp. 241-276). Rio de Janeiro: Academia Brasileira de Ciências.

Klass, K., \& Cords, M. (2011). Effect of unknown relationships on linearity, steepness and rank ordering of dominance hierarchies: Simulation studies based on data from wild monkeys. Behavioural Processes, 88 , $168-176$.

Klass, K., \& Cords, M. (2015). Agonism and dominance in female blue monkeys. American Journal of Primatology, 77, 1299-1315.

Koba, R., Takemoto, A., Miwa, M., \& Nakamura, K. (2012). Characteristics of serial order learning in common marmosets (Callithrix jacchus). Journal of Comparative Psychology, 126, 279-287.

Koenig, A. (2002). Competition for resources and its behavioural consequences among female primates. International Journal of Primatology, 23, 759-783.

Koenig, A., Beise, J., Chalise, M. K., \& Ganzhorn, J. U. (1998). When females should contest for food: Testing hypotheses about resource density, distribution, size, and quality with Hanuman langurs (Presbytis entellus). Behavioural Ecology and Sociobiology, 42, 225-237.

Koenig, A., \& Borries, C. (2006). The predictive power of socioecological models: A reconsideration of resource characteristics, agonism, and dominance hierarchies. In G. Hohmann, M. M. Robbins, \& C. Boesch (Eds.), Feeding ecology in apes and other primates (pp. 263-281). Cambridge: Cambridge University Press.

Koenig, A., Larney, E., Lu, A., \& Borries, C. (2004). Agonistic behaviour and dominance relationships in female Phayre's leaf monkeys: Preliminary results. American Journal of Primatology, 64, 351-357.

Koenig, A., Scarry, C. J., Wheeler, B. C., \& Borries, C. (2013). Variation in grouping patterns, mating systems and social structure: What socioecological models attempt to explain. Philosophical Transactions of the Royal Society B: Biological Sciences, 368, 20120348. 
Králik, M., Koziel, S., \& Ingrova, P. (2014). Changes in digit ratio during puberty: X-ray sample from the Wrocław longitudinal study of twins. The Dolni Věstonice Studies: Mikulov Anthropology Meeting 2014, 20, 187-189.

Kratochvíl, L., \& Flegr, J. (2009). Differences in the 2nd to 4th digit length ratio in humans reflects shifts along the common allometric line. Biology Letters, 5, 643-646.

Lee, H. J., Macbeth, A. H., Pagani, J. H., \& Young, W. S. (2009). Oxytocin: The great facilitator of life. Progress in Neurobiology, 88, 127-151.

Lemelin, P., \& Schmitt, D. (1998). The relation between hand morphology and quadrupedalism in primates. American Journal of Physical Anthropology, 105, 185-197.

Lolli, L., Batterham, A. M., Kratochvíl, L., Flegr, J., Weston, K. L., \& Atkinson, G. (2017). A comprehensive allometric analysis of 2nd digit length to 4th digit length in humans. Proceedings of the Royal Society of London B: Biological Sciences, 284, 20170356.

Manning, J. T. (2002). Digit ratio: A pointer to fertility behaviour and health. New Brunswick, NJ: Rutgers University Press.

Manning, J. T. (2010). Digit ratio (2D:4D), sex differences, allometry, and finger length of 12-30-year olds: Evidence from the British Broadcasting Corporation (BBC) Internet study. American Journal of Human Biology, 22, 604-608.

Manning, J. T., Bundred, P. E., Newton, D. J., \& Flanagan, B. F. (2003). The second to fourth digit ratio and variation in the androgen receptor gene. Evolution and Human Behaviour, 24, 399-405.

Manning, J. T., \& Fink, B. (2018). Digit ratio (2D:4D) and personality and individual differences. The SAGE Handbook of Personality and Individual differences (pp. 40-50). Thousand Oaks, CA: SAGE publications.

Manning, J. T., Stewart, A., Bundred, P. E., \& Trivers, R. L. (2004). Sex and ethnic differences in the 2nd to 4th digit ratio of children. Early Human Development, 80, 161-168.

Martin, P., \& Bateson, P. (2007). Measuring behaviour: An introductory guide (3rd ed.). Cambridge University Press: Cambridge.

Mazur, A., \& Booth, A. (1998). Testosterone and dominance in men. Behavioural and Brain Sciences, 21, 353-397.

McKenna, J. J. (1979). Evolution of allomothering behavior among colobine monkeys: Function and opportunism in evolution. American Anthropologist, 81, 818-840.

Mitchell, C. L. (1994). Migration alliances and coalitions among adult male South American squirrel monkeys (Saimiri sciureus). Behaviour, 130, 169-190.

Mittermeier, R. A., Rylands, A. B., \& Wilson, D. E. (2013). Handbook of the mammals of the world: Vol. 3: Primates. Barcelona: Lynx Edicions.

Nelson, E., Hoffman, C. L., Gerald, M. S., \& Shultz, S. (2010). Digit ratio (2D:4D) and dominance rank in female rhesus macaques (Macaca mulatta). Behavioural Ecology and Sociobiology, 64, 1001-1009.

Nelson, E., \& Shultz, S. (2010). Finger length ratios (2D:4D) in Anthropoids implicate reduced prenatal androgens in social bonding. American Journal of Physical Anthropology, 141, 395-405.

Neumann, I. D. (2008). Brain oxytocin: A key regulator of emotional and social behaviours in both females and males. Journal of Neuroendocrinology, 20, 858-865.

Oates, J. F., Gippoliti, S., \& Groves, C. P. (2016). Cercocebus lunulatus. The IUCN Red List of Threatened Species 2016, e. T4206A92247225. 10.2305/IUCN.UK.2016-1.RLTS.T4206A92247225.en.

Parish, A. R. (1994). Sex and food control in the "uncommon chimpanzee": How bonobo females overcome a phylogenetic legacy of male dominance. Ethology \& Sociobiology, 15, 157-179.

Pastorini, J., Forstner, M. R. J., \& Martin, R. D. (2001). Phylogenetic history of sifakas (Propithecus: Lemuriformes) derived from mtDNA sequences. American Journal of Primatology, 53, 1-17.

Pereira, M. E., Kaufman, R., Kappeler, P. M., \& Overdorff, D. J. (1990). Female dominance does not characterise all of the Lemuridae. Folia Primatologica, 55, 96-103.

Perelman, P., Johnson, W. E., Roos, C., Seuánez, H. N., Horvath, J. E., et al (2011). A molecular phylogeny of living primates. PLoS Genetics, 7, e1001342.

Petty, J. M. A., \& Drea, C. M. (2015). Female rule in lemurs is ancestral and hormonally mediated. Scientific Reports, 5, 9631.

Pomerantz, S. M., Goy, R. W., \& Roy, M. M. (1986). Expression of male-typical behavior in adult female pseudohermaphroditic rhesus: Comparisons with normal males and neonatally gonadectomized males and females. Hormones and Behavior, 20, 483-500.

Pomerantz, S. M., Roy, M. M., Thornton, J. E., \& Goy, R. W. (1985). Expression of adult female patterns of sexual behavior by male, female, and pseudohermaphroditic female rhesus monkeys. Biology of Reproduction, 33, 878-889. 
Raemaekers, J. J., \& Raemaekers, P. M. (1985). Field playback of loud calls to gibbons (Hylobates lar): Territorial, sex-specific and species-specific responses. Animal Behaviour, 33, 481-493.

Range, F., \& Noë, R. (2002). Familiarity and dominance relations among female sooty mangabeys in the Taï National Park. American Journal of Primatology, 56, 137-153.

Ranson, R. M., Taylor, S. R., \& Stratton, G. (2013). Reliability of a field based 2D:4D measurement technique in children. Early Human Development, 89, 589-592.

Reichard, U. H., \& Barelli, C. (2008). Life history and reproductive strategies of Khao Yai Hylobates lar: Implications for social evolution in apes. International Journal of Primatology, 29, 823-844.

Richmond, B. G. (2007). Biomechanics of phalangeal curvature. Journal of Human Evolution, 53, 678-690.

Robbins, M. M., Robbins, A. M., Gerald-Steklis, N., \& Steklis, H. D. (2005). Long-term dominance relationships in female mountain gorillas: Strength, stability and determinants of rank. Behaviour, 142, 779-809.

Roney, J. R., Whitham, J. C., Leoni, M., Bellem, A., Wielebnowski, N., \& Maestripieri, D. (2004). Relative digit lengths and testosterone levels in Guinea baboons. Hormones and Behavior, 45, 285-290.

Rosvall, K. A. (2011). Intrasexual competition in females: Evidence for sexual selection? Behavioral Ecology, 22, 1131-1140.

Saltzman, W., Digby, L. J., \& Abbott, D. H. (2009). Reproductive skew in female common marmosets: What can proximate mechanisms tell us about ultimate causes? Proceedings of the Royal Society B: Biological Sciences, 276, 389-399.

Savage, A., Ziegler, T. E., \& Snowdon, C. T. (1988). Sociosexual development, pair bond formation, and mechanisms of fertility suppression in female cotton-top tamarins (Saguinus oedipus oedipus). American Journal of Primatology, 14, 345-359.

Schülke, O., \& Kappeler, P. M. (2003). So near and yet so far: territorial pairs but low cohesion between pair partners in a nocturnal lemur, Phaner furcifer. Animal Behaviour, 65, 331-343.

Snaith, T. V., \& Chapman, C. A. (2007). Primate group size and interpreting socioecological models: do folivores really play by different rules? Evolutionary Anthropology, 16, 94-106.

Soares, M. C., Bshary, R., Fusani, L., Goymann, W., Hau, M., et al (2010). Hormonal mechanisms of cooperative behaviour. Philosophical Transactions of the Royal Society B: Biological Sciences, 365, 2737-2750.

Steenbeek, R., \& van Schaik, C. P. (2001). Competition and group size in Thomas's langurs (Presbytis thomasi): The folivore paradox revisited. Behavioural Ecology and Sociobiology, 49, 100-110.

Sterck, E. H. M., Watts, D. P., \& van Schaik, C. P. (1997). The evolution of female social relationships in nonhuman primates. Behavioural Ecology and Sociobiology, 41, 291-309.

Strier, K. B. (1990). New World primates, new frontiers: Insights from the woolly spider monkey, or muriqui (Brachyteles arachnoides). International Journal of Primatology, 11, 7-19.

Terborgh, J., \& Janson, C. H. (1986). The socioecology of primate groups. Annual Review of Ecology, Evolution and Systematics, 17, 111-135.

Thalmann, U., Kümmerli, R., \& Zaramody, A. (2002). Why Propithecus verreauxi deckeni and P. v. coronatus are valid taxa: Quantitative and qualitative arguments. Lemur News, 7, 11-16.

Thankamony, A., Pasterski, V., Ong, K. K., Acerini, C. L., \& Hughes, I. A. (2016). Anogenital distance as a marker of androgen exposure in humans. Andrology, 4, 616-625.

Thierry, B. (2008). Primate socioecology, the lost dream of ecological determinism. Evolutionary Anthropology, 17, 93-96.

Trivers, R. L. (1972). Parental investment and sexual selection. In B. Campbell (Ed.), Sexual selection and the descent of man 1871-1971 (pp. 136-179). Chicago: Aldine.

Trumble, B. C., Jaeggi, A. V., \& Gurven, M. (2015). Evolving the neuroendocrine physiology of human and primate cooperation and collective action. Philosophical Transactions of the Royal Society B: Biological Sciences, 370, 20150014.

van Hooff, J., \& Wensing, J. (1987). Dominance and its behavioural measures in a captive wolf pack. In H. Frank (Ed.), Man and wolf (pp. 219-252). Dordrecht: W. Junk.

van Hooff, J. A., \& van Schaik, C. P. (1994). Male bonds: Affiliative relationships among nonhuman primate males. Behaviour, 130, 309-337.

van Schaik, C. P. (1983). Why are diurnal primates living in groups? Behaviour, 87, 120-144.

van Schaik, C. P. (1989). The ecology of social relationships amongst female primates. In V. Standen (Ed.), Comparative socioecology (pp. 195-218). Oxford: Blackwell.

van Schaik, C. P., \& van Hooff, J. A. R. A. M. (1983). On the ultimate causes of primate social systems. Behaviour, 85, 91-117.

Voracek, M., Manning, J. T., \& Dressler, S. G. (2007). Repeatability and interobserver error of digit ratio (2D: 4D) measurements made by experts. American Journal of Human Biology, 19, 142-146. 
Waeber, P. O., \& Hemelrijk, C. K. (2003). Female dominance and social structure in Alaotran gentle lemurs. Behaviour, 140, 1235-1246.

Wallen, K. (2005). Hormonal influences on sexually differentiated behavior in nonhuman primates. Frontiers in Neuroendocrinology, 26, 7-26.

Wallen, K., \& Hassett, J. M. (2009). Sexual differentiation of behaviour in monkeys: Role of prenatal hormones. Journal of Neuroendocrinology, 21, 421-426.

Wheeler, B. C., Scarry, C. J., \& Koenig, A. (2013). Rates of agonism among female primates: A cross-taxon perspective. Behavioural Ecology, 24, 1369-1380.

Wikberg, E. C., Teichroeb, J. A., Bặdescu, I., \& Sicotte, P. (2013). Individualistic female dominance hierarchies with varying strength in a highly folivorous population of black-and-white colobus. Behaviour, 150, 295-320.

Wikberg, E. C., Ting, N., \& Sicotte, P. (2014). Kinship and similarity in residency status structure female social networks in black-and-white colobus monkeys (Colobus vellerosus). American Journal of Physical Anthropology, 153, 365-376.

Williams, J. H. G., Greenhalgh, K. D., \& Manning, J. T. (2003). Second to fourth finger ratio and developmental psychopathology in preschool children. Early Human Development, 72, 57-65.

Yeager, C. P., \& Kool, K. (2000). The behavioural ecology of Asian colobines. In P. F. Whitehead \& C. J. Jolly (Eds.), Old world monkeys (pp. 496-514). Cambridge: Cambridge University Press.

Zeigler, T. E., \& Crockford, C. (2017). Neuroendocrine control in social relationships in non-human primates: Field-based evidence. Hormones and Behaviour, 91, 107-121.

Zheng, Z., \& Cohn, M. J. (2011). Developmental basis of sexually dimorphic digit ratios. Proceedings of the National Academy of Sciences of the USA, 108, 16289-16294. 